Chelladurai Sree Krishna Prabu

Nagarajan Vishwanath

Sha Om Prakash

http://dx.doi.org/10.21278/brod71304

ISSN 0007-215X

eISSN $1845-5859$

\title{
STUDY ON THE LIGHTSHIP CHARACTERISTICS OF MERCHANT SHIPS
}

UDC 629.5.012:629.5.013:629.5.012.64:629.5.015.1

Original scientific paper

\section{Summary}

Lightship weight and its distribution have significant influence on the intact/ damage stability and longitudinal strength of the ship. In this study, the range of limiting lightship longitudinal and vertical centre of gravity for different types of merchant ships have been determined. The merchant ships considered are bulk carriers, crude oil tankers, liquefied gas carriers, container ships and pure car carriers. Detailed hull form and general arrangement layout of the merchant ships were developed. Applicable rules and regulations and design considerations for each type of merchant ships were considered for this purpose. The principal dimensions, form coefficients, powering, stability and statutory rules and regulations are matched to the ships in service. At this stage, different rules and regulations concerning ship's stability and trim were considered. Finally, after deducting the vertical and longitudinal center of gravity of the deadweight components (cargo, fuel and fresh water), the limiting lightship vertical and longitudinal center of gravity are determined.

Key words: $\quad$ Primary dimensions; lightweight; intact; damage stability; limiting lightship longitudinal center of gravity; limiting lightship vertical center of gravity

\section{Introduction}

Ship design is considered more art than science. The design is continually improved based on the experience gained from similarly built ship types. The knowledge obtained from existing ships is converted as semi-empirical formula and statistical data. Ship designers while optimizing ship design consider various aspects like, carrying capacity, propulsion efficiency, construction cost and freight rate. Besides above safety of crew, cargo and structural integrity must be satisfied. Last but not the least, the design should have minimum environmental impact. Some of the design requirements are contradictory. Therefore, rational choice should be made for owner's requirements. Merchant ships can be divided into two categories, i.e. deadweight carriers and volume carrier. Deadweight carriers carry relatively dense cargoes having stowage factor about $1.3 \mathrm{~m}^{3} / \mathrm{t}$ [1]. Typical examples of this ship category are bulk carriers and tankers. Volumetric carriers carry relatively less dense cargo having stowage factor more than $2.0 \mathrm{~m}^{3} / \mathrm{t}$ [1]. Typical examples of this ship category are the 
passenger ships, containerships, car carriers, LNG and LPG carrier. An important feature of volumetric carriers is large hold volume. In ship design process, selection of length, beam, draft, depth, block coefficient, prismatic coefficient and displacement are important elements. This order is applied to deadweight carriers and logically modified for volumetric carriers [1]. The basic characteristics of different ship's lightship components, typical sizes and percentages of weight groups for merchant ships were estimated [2] and updated by Papanikolaou [1]. In this work [1], the variation of ship characteristics have been presented with respect to ratios of principal particulars $(L / B, B / T, L / D$ etc). Statistical analysis of upper and lower boundaries of hull form coefficients and ratios of main dimensions for merchant ships were carried out by Strohbusch E. and updated by Papanikolaou [1]. As per statutory regulations [3], the permissible variation of a ship's lightship displacement is less than $2 \%$ of the lightship displacement and of the lightship's longitudinal centre of gravity it is less than $1 \%$ of ship's length [3]. If the variation is higher, then an inclining experiment needs to be carried out to determine the new lightship vertical centre of gravity. This shows the influence of these parameters on the ship's stability. Sensitivity analysis of the probabilistic damage stability regulations for Ro-Pax vessel was estimated [4]. Investigation of one large Ro-Pax ship was carried out, to document the underlying and emerging trends of Ro-Pax ship design which will help the designer at the early stages. Very few ships have been designed till date on the basis of probabilistic subdivision regulations. Typical large Ro-Pax vessel was investigated with variation of parameters, like number, position and optimization of transverse bulkheads. Also the presence and position of longitudinal bulkheads below the main vehicle deck, the presence of side casings, and the height of the main deck and double bottom were considered. Probabilistic damage stability framework was developed to enhance passenger, ship safety in the maritime industry [5]. The probabilistic framework of the new rules for damage stability offers flexibility and added degrees of freedom for designers to enhance safety cost-effectively. Now the trend is towards probabilistic and risk based frameworks to address ship safety in a scientific manner. Therefore, it is important to understand the principles and the intention of the ensuing rules and criteria. The problems faced by the marine industry to cross the bridge from rules-based to risk-based design need to be put into practice. This paper [5] demonstrates that requirement of scientific and technological developments are in hand for risk-based design to be fully implemented in the maritime industry. The optimization of diesel electric machinery system for conceptual ship design was presented to support selecting the configuration of diesel engines in a machinery system [6]. The model aims at minimizing investment and operational costs over the ship's lifetime when the ship's operational profiles are assumed to be known. The load distribution on the engines is considered in the model to ensure that required demand is met with sufficient power supply for all future operational states. A method for fuel consumption calculation is presented, based on determining optimal load distribution amongst the engines generalized specific fuel consumption curve. A parametric method was developed to determine the steel weight for each main structure to estimate the global design factors with a lower average error than other methods [7]. This measurement decisively influences the weight calculation and is also a critical cost item in the tender of a new shipbuilding contract. The principal component analysis is applied to find the principal influence parameters, including the global and local design factors, and to calculate the weighting values for each parameter. The obtained weight distribution to support the various aspects of preliminary design, help to determine the center of gravity, the design of the ship lines and ship performance evaluation. Cudina and Bezic [8] evaluated the economics of operating reefer vessels and container ships for carrying same amount of refrigerated cargo. Detailed general arrangement design of a reefer ship and a container ship were carried out. Fuel consumption for maintaining the cargo temperature and for completing similar voyages were compared. It was concluded that the reefer ship's 
operation is quite economical and further development and improvement of their design was recommended. Kalajdžic and Momcilovic [9] developed a procedure for determining the characteristics of an optimum multi purpose cargo vessel in the preliminary design stage. Statistical analysis of successful multi purpose cargo ships built over the past 30 years was carried out. Using the proposed set of diagrams and formulas, the ship's principal dimensions were determined based upon required deadweight as a main prerequisite, as well as optimum energy efficiency design index, tank capacities, lightweight, etc. It was also concluded that preliminary design stage is very important, as once the main ship parameters are estimated the design cannot be repaired later. All the above studies show that improvement in estimation of ship particulars in preliminary design stage for different ship types still needs improvement. For some specialized ship types the design charts for preliminary ship design may not be available in public domain. This paper is a contribution to the preliminary design process for some popular merchant ship types. In the present study, the approach is as follows. Hull form and general arrangement design for different types of merchant ships are developed using commercial design software $\left(\right.$ Maxsurf $\left.{ }^{\circledR}\right)$. For this purpose, the rules and regulations for the applicable ship types are complied with. The lightship weight and its distribution are determined using existing regression formula and the ship design characteristics. Thereafter we apply statutory rules and regulations regarding intact and damage stability for the different ship types. It is well known that maximum permissible $\overline{K G}$ for ship can be obtained based on these requirements. Similarly, the forward and aft limit of the ship's $L_{\mathrm{CG}}$ is determined. The centroid of deadweight components are thereafter determined based on the actual tank layout and load distribution. Finally, the deadweight component moments are deducted and the limiting lightship vertical centre of gravity $\left(K G_{\mathrm{LS}}\right)$ and limiting longitudinal centre of gravity $\left(L C G_{\mathrm{LS}}\right)$ is determined. Based on the analysis, we show the variation of lightship weight and its centroid for different merchant ship types.

\section{Design of ships}

The accompanying analysis is based on 58 different hull forms. The hull forms consist of crude oil tanker, chemical tanker, bulk carrier, container ship, LNG, LPG carrier and pure car carrier. The numbers of ship and main dimensions are described in Table 1. The principal dimensions were selected from statistical data of previously built ships. That provides a good starting point for developing the particulars of hull form and primary dimensions of ships. In initial design stage, the mission requirements are translated into technical characteristics of shipbuilding nature. 
Table 1 Details of different ship types considered for analysis

\begin{tabular}{|c|c|c|c|c|c|c|c|c|c|c|c|}
\hline Sr. no. & Ship type & & Main & limer & ions & $\mathbf{x} \mathbf{B}$ & $\mathbf{D}$ & and ye & $\operatorname{ar}$ of 1 & uilt & \\
\hline \multirow[b]{5}{*}{1.} & \multirow[b]{5}{*}{ Bulk carrier } & 1 & 116 & 18 & 9.1 & 2010 & 5 & 191.5 & 33 & 18.5 & 2017 \\
\hline & & 2 & 180 & 26 & 14 & 2008 & 6 & 225 & 33 & 20.2 & 2011 \\
\hline & & 3 & 180 & 32.3 & 18 & 2011 & 7 & 233 & 32.2 & 19.1 & 2008 \\
\hline & & 4 & 184 & 32.2 & 17.1 & 2007 & 8 & 301 & 46.5 & 24.6 & 2009 \\
\hline & & & & & & & 9 & 221 & 36.8 & 19.9 & 2010 \\
\hline \multirow[b]{4}{*}{2.} & \multirow[b]{4}{*}{ Car carrier } & 1 & 128 & 23.4 & 21 & 2016 & 5 & 188 & 32.2 & 33.7 & 2007 \\
\hline & & 2 & 165 & 31.1 & 30 & 2008 & 6 & 190 & 32.2 & 34.7 & 2010 \\
\hline & & 3 & 181 & 25 & 26 & 2016 & 7 & 194 & 32.2 & 32.3 & 2007 \\
\hline & & 4 & 185 & 32 & 32 & 2010 & 8 & 222.4 & 32.2 & 33.7 & 2008 \\
\hline \multirow[b]{4}{*}{3.} & \multirow{4}{*}{$\begin{array}{l}\text { Chemical } \\
\text { tanker }\end{array}$} & 1 & 114 & 17.4 & 9.7 & 2008 & 5 & 177 & 32.2 & 18.5 & 2014 \\
\hline & & 2 & 135 & 16.6 & 6.8 & 2010 & 6 & 187 & 32 & 17 & 2016 \\
\hline & & 3 & 146 & 26 & 13.5 & 2007 & 7 & 219 & 32.2 & 20.9 & 2007 \\
\hline & & 4 & 158 & 27 & 15 & 2008 & 8 & 240 & 42 & 21.5 & 2014 \\
\hline \multirow[b]{4}{*}{4.} & \multirow{4}{*}{$\begin{array}{l}\text { Container } \\
\text { carrier }\end{array}$} & 1 & 128 & 22.8 & 14 & 2007 & 5 & 249 & 32.2 & 19.5 & 2007 \\
\hline & & 2 & 175 & 27.6 & 17.1 & 2006 & 6 & 265 & 40 & 24 & 2007 \\
\hline & & 3 & 185 & 30 & 17 & 2015 & 7 & 312.5 & 42.3 & 24 & 2008 \\
\hline & & 4 & 214 & 37.5 & 19.1 & 2007 & 8 & 318 & 47 & 26.6 & 2016 \\
\hline \multirow[b]{5}{*}{5.} & \multirow{5}{*}{$\begin{array}{l}\text { Crude } \\
\text { tanker }\end{array}$} & 1 & 174 & 32.2 & 19.1 & 2007 & 5 & 263 & 46 & 23 & 2008 \\
\hline & & 2 & 175 & 32 & 17 & 2016 & 6 & 274 & 48 & 22 & 2007 \\
\hline & & 3 & 218.5 & 32.2 & 20.4 & 2010 & 7 & 320 & 60 & 27.1 & 2010 \\
\hline & & 4 & 243.5 & 40.5 & 22 & 2016 & 8 & 345 & 60 & 26 & 2010 \\
\hline & & & & & & & 9 & 236 & 42 & 21 & 2009 \\
\hline \multirow[b]{4}{*}{6.} & \multirow[b]{4}{*}{ LNG carrier } & 1 & 262 & 41.5 & 26.2 & 2010 & 5 & 280 & 46.5 & 26.5 & 2016 \\
\hline & & 2 & 264 & 46.8 & 26 & 2016 & 6 & 280 & 48.9 & 27 & 2016 \\
\hline & & 3 & 269.5 & 42 & 26 & 2016 & 7 & 303 & 50 & 27.4 & 2007 \\
\hline & & 4 & 277 & 49 & 27 & 2008 & 8 & 335 & 55 & 30 & 2008 \\
\hline \multirow[b]{4}{*}{7.} & \multirow[b]{4}{*}{ LPG carrier } & 1 & 85 & 15 & 7.6 & 2012 & 5 & 155 & 26 & 16 & 2010 \\
\hline & & 2 & 94 & 17.5 & 11.7 & 2006 & 6 & 156 & 25.6 & 16.4 & 2016 \\
\hline & & 3 & 111 & 19 & 9.3 & 2014 & 7 & 194.8 & 32.2 & 20.8 & 2012 \\
\hline & & 4 & 113 & 19.8 & 11.2 & 2007 & 8 & 213.5 & 36.6 & 22.2 & 2013 \\
\hline
\end{tabular}

\subsection{Design considerations for hull form design}

The present work deals with the first two phases (Fig. 1) of ship design, i.e. preliminary design and concept design. Preliminary design is an elaboration of the various ship-design steps, partly addressed in the first phase. It involves an accurate determination of ship's principal characteristics namely, length, beam, depth, draft, block coefficient and effective powering. It is understood that calculating the above parameters of the ship is subject to 
compliance with national and international maritime rules. The primary ship dimensions (length, beam, draft, depth), and hull form characteristics (hull form coefficients, powering, weight components, stability and trim, freeboard, load line), are required in the first phase of ship design. After selecting the above basic ship design elements followed by the estimation of the lightship weight, the displacement of ship is calculated.

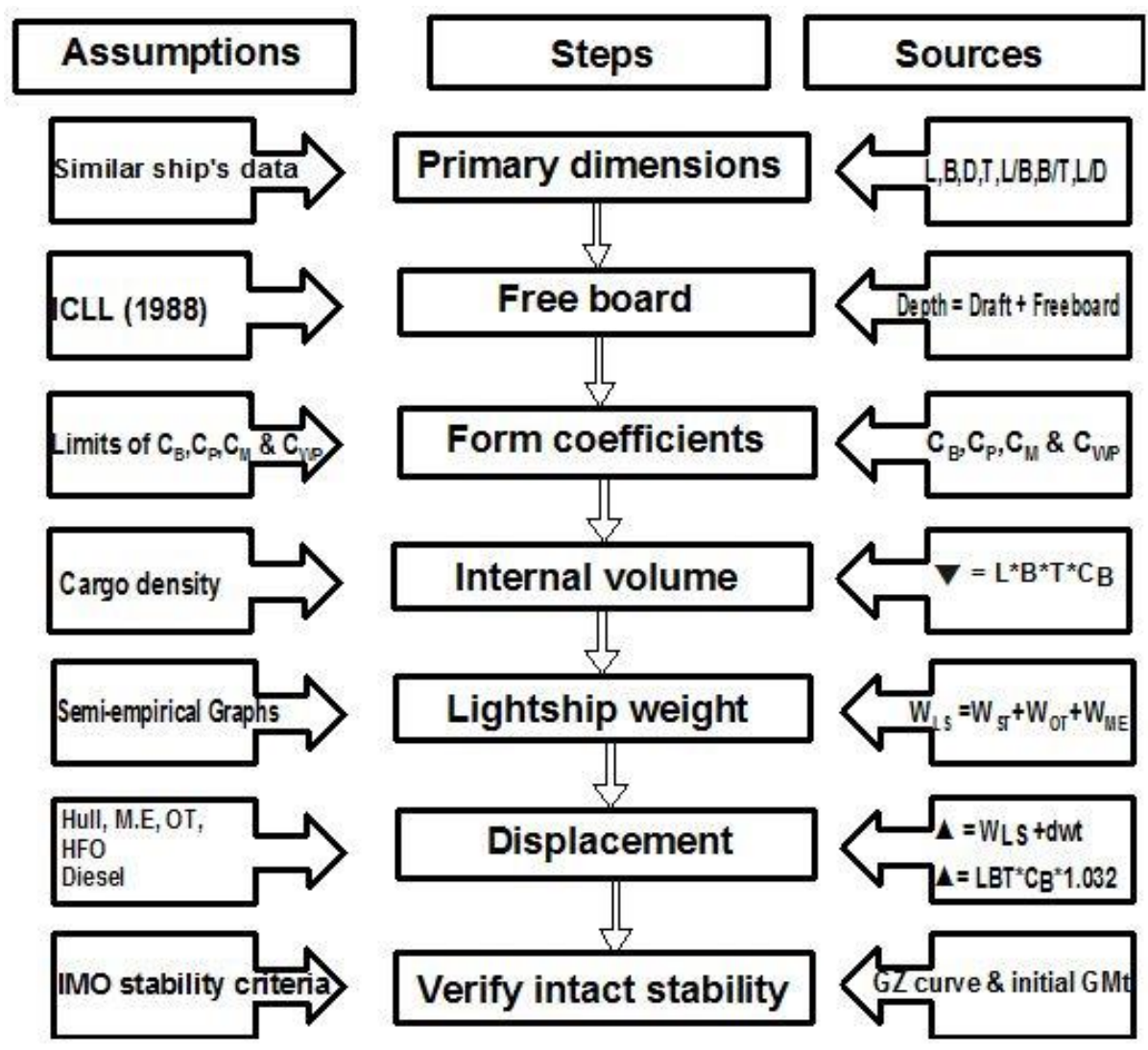

Fig. 1 Iterative procedure of estimation of main parameters

The selection of primary dimensions and form coefficients are based on statistical data, empirical design formulas, coefficient tables and graphs. The above characteristics are guide to design individual ship type. For all ship types, we should refer the limitations of principal dimensions (length, beam, draft and depth) based on limitations of ports of call. Besides above, there are restrictions because of transiting canals, for e.g. Panama Canal, St. Lawrence Seaway and Suez Canal. The estimation of main dimensions is based on data available from the similarly built ship, commercial and internal databases. The equivalent data and semiempirical formulas are sufficient for the successful application of the empirical method. The ship's principal dimensions, weight components and powering requirement are dependent on each other. For displacement ships, for small variation of ship's length, the variation in ship's resistance and powering may be proportionate [1]. The data of principal dimensions and coefficients of similar ships help to reduce the design work. It also serves as validation for computer generated design data. Typical data required for designing different ship types are shown in Table 2 [1]. 
Table 2 Main particular from similar ship

\begin{tabular}{|l|l|l|}
\hline Sr. no. & Type of ship & Similar ship main particulars \\
\hline 1. & Bulk carriers & $\begin{array}{l}\text { Deadweight, speed, main machinery powering, passing } \\
\text { limits through canals }\end{array}$ \\
\hline 2. & Car carrier & $\begin{array}{l}\text { Deadweight, number of cars (above and below deck), } \\
\text { speed, powering, and passing limits through canals. }\end{array}$ \\
\hline & Container ships & $\begin{array}{l}\text { Deadweight, number of containers (above and below } \\
\text { deck, number of TEU and FEU), speed, powering, and } \\
\text { passing limits through canals. }\end{array}$ \\
\hline 4. & LNG/ LPG carrier & $\begin{array}{l}\text { Deadweight, refrigerated cargo hold volume } \\
\text { speed, powering }\end{array}$ \\
\hline 5. & Tankers & $\begin{array}{l}\text { Deadweight, speed, powering, passing limits through } \\
\text { canals and narrow straits }\end{array}$ \\
\hline
\end{tabular}

In this paper, the sequence of determining the primary dimensions and form coefficients are briefly described. We first present the principles for the selection of the primary dimensions and secondly, the different semi-empirical formulas. The procedure for selecting the main dimensions and form coefficients are based on an iterative approach shown in Fig. 1. The displacement and speed are primarily dependent on the ship's length. It has a significant influence on the hull weight, machinery and outfitting. It also reflects on the construction cost and, it has a strong influence on the ship's resistance and sea keeping performance. Froude number is representative of the ship's speed. The tanker and bulk carriers have high $C_{\mathrm{B}}$ and $C_{\mathrm{P}}$ coefficients with low Froude number up to 0.20. The above form corresponds to full hull. They have high frictional resistance as a percentage of total resistance [2]. For reduction of frictional resistance, ships must have minimum wetted surface for a given displacement. On the other hand, container and passenger ships have low $C_{\mathrm{P}}$ and $C_{\mathrm{B}}$ coefficients with high Froude number above 0.25 . They have a significant proportion of wave/ residuary resistance as a percentage total resistance. To reduce the wave resistance, relatively slender hulls are designed. For other types of ships the percentage share of the residuary and frictional resistance components may differ with total resistance [10]. The position of longitudinal centre of buoyancy varies depending on the longitudinal distribution of displacement. The basic influencing factors of main dimensions on the steel and outfitting, and the effect of speed on the lightship weight were investigated by Strohbusch [1]. Strohbusch also investigated the effect of slenderness ratio and prismatic coefficient on ship hull performance [1]. Ship's beam has significant influence on stability. An increase of beam by $10 \%$ leads approximately to a rise in $\overline{G M_{T}}$ by $30 \%$ [11]. Propeller diameter depends on the draft of the ship. High draft vessels, like tankers and bulk carriers are fitted with a large diameter propeller for achieving higher efficiency with the low propeller revolution. This is because higher diameter propeller will have lower revolution. Also, the size of the rudder is large for better manoeuvrability. Limitation of draft involuntarily increases the primary dimensions especially the beam of ship. While selecting the draft of the ship, the depth of the navigation route, water depth of the calling ports, channels, canals, estuaries, bays, and narrow sea straits must be checked. The selection of the depth is inherently linked to the permissible draft. Indirectly, it is related to the ship's length (in consideration of the longitudinal strength) and beam (in consideration of the transverse stability). For example, 
increase of depth by $10 \%$ causes an increase of the steel weight by $8 \%$ for $L / D=10$ or by $4 \%$ for $L / D=14$ [2]. One prefers an increase of the ship's depth rather than changes of other main dimensions in case the ship's hold volume is inadequate. The depth is the "cheapest" and least problematic primary dimension of a ship. Classification societies define a limit of the $L / D$ ratio, which varies between 10 to 14 [12]. If $L / D>14$, then a special investigation of longitudinal strength is required. Increase of the depth means reduction of the ratio $L / D$. Due to the increase in section modulus, ship's longitudinal bending stress will reduce. The increase in depth results in the increase of the hull weight and rise in vertical center of gravity of the hull [1]. Also, the weight of superstructures and outfitting increases accordingly. This leads to an increase of the ships $\overline{K G}$ in all the load conditions. The loadline rules consider $L / D$ ratio of a standard ship as 15 . If the actual $L / D$ ratio is lower, then the freeboard has to be increased. Here the idea is to have sufficient reserve buoyancy for ship motions in waves and also during damage stability. The $B / T$ ratio has a strong influence on the residuary resistance of the ship. It decides the contribution of wave making resistance to the total resistance of the ship. It is preferred to have the $B / T$ around 2.5 [1].

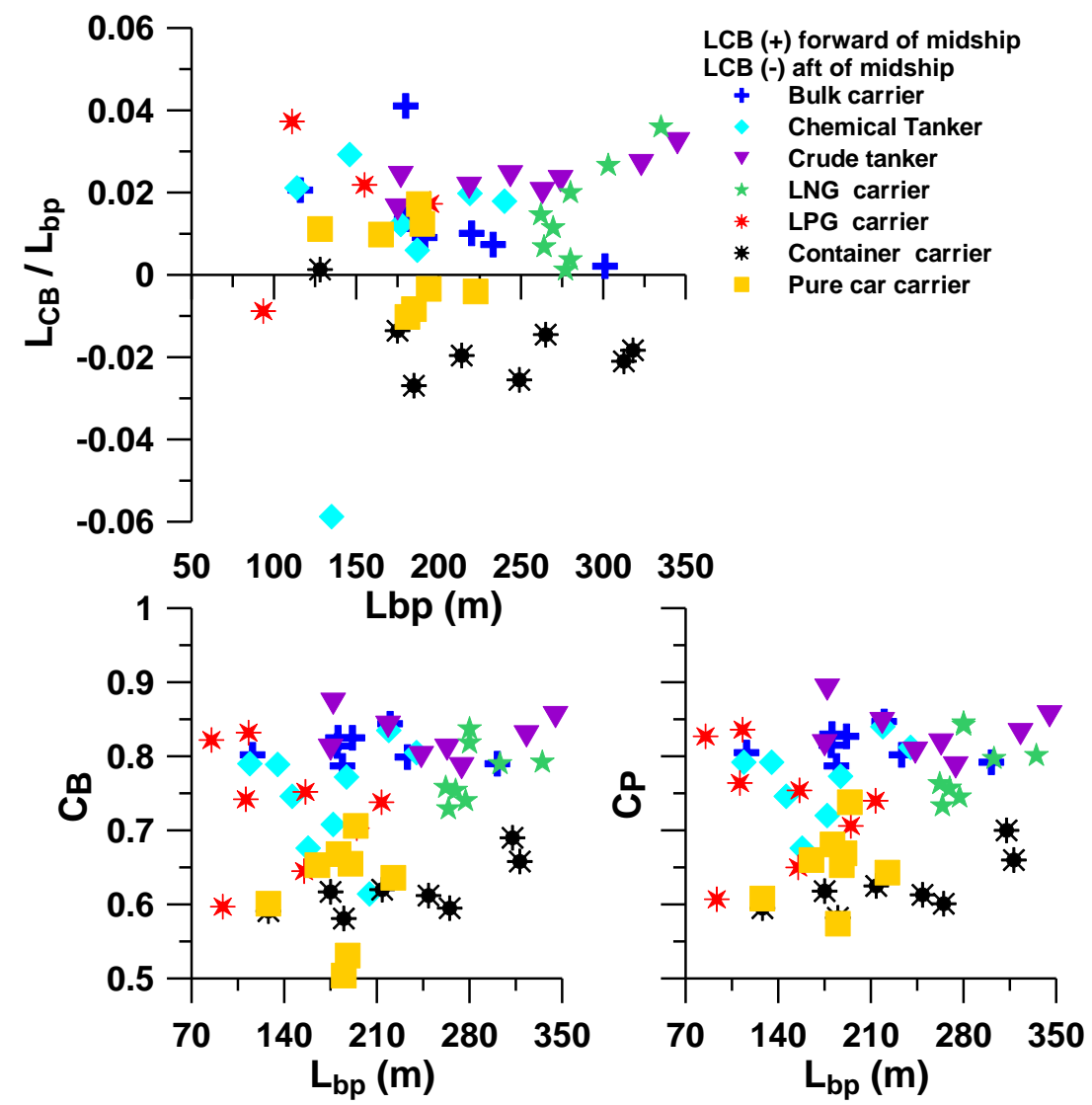

Fig. 2 Variation of different form coefficients with length for different ship types.

The $L / B$ ratio has an influence on the wave resistance of ship. The lower $L / B$ ratio has an increased effect on wave resistance. The increased beam (reduced $L / B$ ratio) improves the maneuverability of the ship [1]. As discussed before, container ships and car carriers have comparatively slim hull. This means $C_{\mathrm{P}}$ and $C_{\mathrm{B}}$ values are low and $\mathrm{Fr}$ is higher as shown in Fig. 2. In container ships, due to low $C_{\mathrm{P}}$, there is concentration of loaded containers in the midship region below deck. To compensate for this, container ships are provided with large flare at the forward and aft section for accommodating the containers on deck. Similarly, in PCCs, huge space is provided above the freeboard deck throughout the 
length of the ship to accommodate the cars/ trucks. Both the ship types have reduced lower deck spaces and sharp entrance in the bow region which helps to achieve the relatively high speed. Figure 2 describes the position of $L_{\mathrm{CB}}$ for dead weight and volumetric carriers. The $L_{\mathrm{CB}}$ of the container ships and car carriers are located aft of mid ship, while for the bulk carrier and tanker vessel it is located forward of mid ship. Load Line Regulations need to be complied with to achieve the minimum freeboard and bow height for all designs [13]. The minimum freeboard requirements are classified in two categories. Oil tankers/ gas carriers come under 'type $\mathrm{A}^{\prime}$ and dry cargo ships come under 'type B' category. The required freeboard is calculated based on the length of the ship. Thereafter corrections based on the $C_{\mathrm{B}}(0.68)$, depth, sheer of the ship is applied on the tabular freeboard [13]. Figure 3 describes the minimum freeboard requirement for different length of ship. From Fig. 3 it is understood, that the volumetric carriers have high freeboard/ depth ratio as compared with the deadweight carriers. High freeboard ensures that there is sufficient reserve buoyancy and better survivability in case of hull damage.

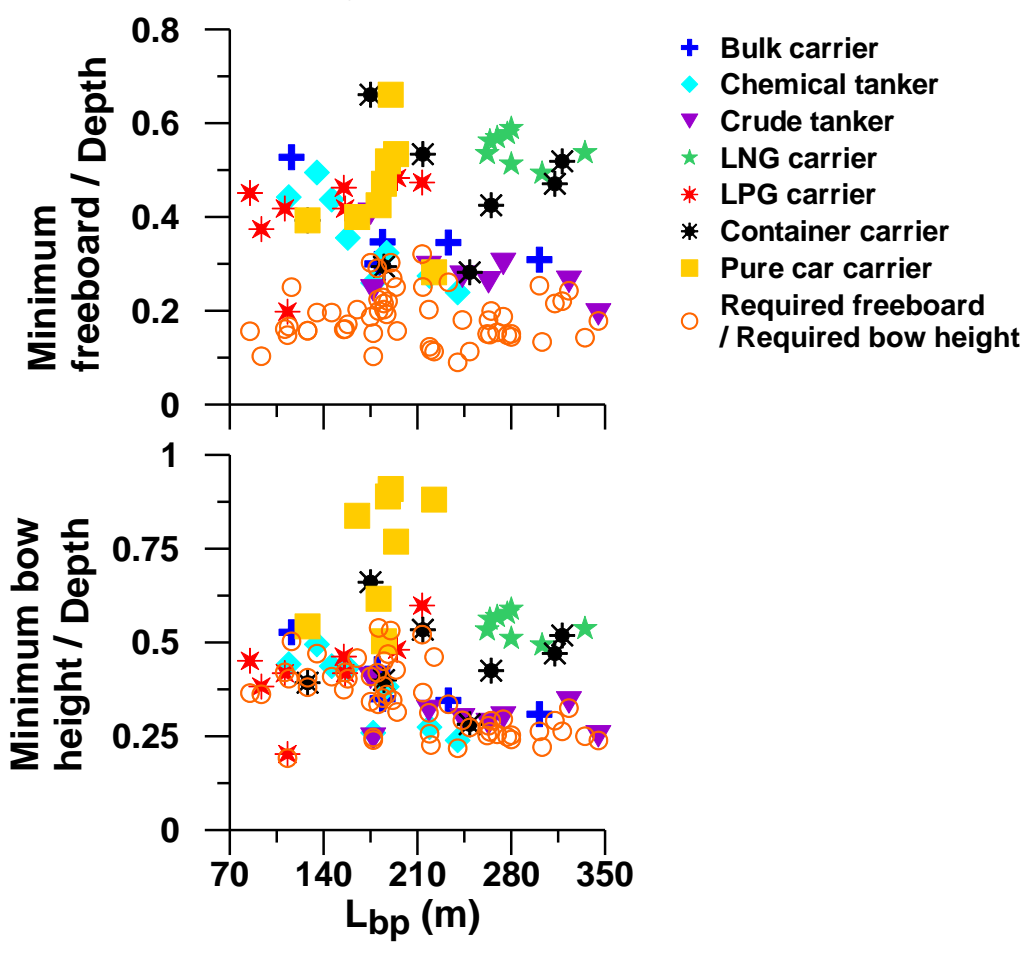

Fig. 3 Variation of minimum freeboard and bow height with length for different ship types.

The bow height, is measured at forward perpendicular between summer load line and the ship's weather deck or the forecastle deck. Minimum bow height is calculated based on the regression formula proposed in loadline regulation [13]. All bulk carrier ships are provided with forecastle as per the loadline regulations [13]. Some of the container ships and small LPG ships are also provided with forecastle complying with loadline regulations. Some LPG ships and oil tankers are provided with poop deck meeting the loadline regulations. Figure 3 shows the freeboard and bow height provided for various ships. The minimum value required by regulation is also plotted. It is observed that the volumetric carriers have relatively large freeboard than the dead weight carriers. The freeboard and the bow height for all types of ships is more than the regulatory requirement. The large bow height helps to reduce the risk of green-water thereby giving protection against damage of deck cargo or containers due to large pitching and heaving motions. 


\subsection{Design considerations for general arrangement design}

The next stage of ship design is general arrangement. The general arrangement provides the location/ dimension and extent of engine room, cargo compartment. It also shows the type and number of bulkheads to be provided on the ship. Using this information along with the volume and density of cargo in individual compartments, the $L_{\mathrm{CG}}$ and $\overline{K G}$ position for different loading conditions can be estimated. This information is used to calculate the stability of ship at a later stage. First, the common regulations applicable for all the ship types will be described. Forepeak bulkhead is fitted as per classification society's regulations. Classification society's rules also specify the minimum number of transverse bulkheads for various ship types. This mainly depends on the type and length of the ship. Transverse bulkheads need to be located along the length of the ship both from the aspect of strength and distribution of volume in different cargo holds. This is because for the same length, we get lower volume in the forward and aft part of the ship due to the narrow ship sections. All ships are provided with a forward and an aft peak bulkhead. The distance between the forward collision bulkhead from the forward perpendicular must be within the limits of $5 \%$ or $10 \mathrm{~m}$ and $8 \%$ of $L_{\mathrm{bp}}$ as specified by class rules. From Fig. 4, it is observed that most of the ships have forepeak tank length nearing the upper limit. This is because the ships need to achieve minimum draft at forward in the ballast condition for protection against bottom slamming. The after peak bulkhead is located such that the length of the propeller shaft is less than the intermediate shaft. This is for the ease of maintenance of propeller shaft. Steering gear deck is provided as per the parent ship configuration. The aft peak bulkhead location is also decided based on the required capacity of the aft peak tank. The length of the engine room compartment depends on ship's lines plan, the propulsive machinery power and displacement of ship. In this study, it is based on the similar ship types. When the engine room is at aft, the aft peak bulkhead coincides with the aft bulkhead of the engine room. The aft peak bulkhead location is also based on the requirement of minimum volume of ballast required in aft peak tank for trimming purpose. It is evident from Fig. 4, that the tankers and liquid gas carrier have larger engine room length. The reason is tankers and liquid gas carriers have a pump room in the forward part of the engine room. The pump room contains cargo/ ballast pumps for loading/ unloading the cargo and ballast. The machinery for driving the cargo/ ballast pumps is located in the forward part of the engine room in these ships. Also in these ships, engine room is located in aft. Due to narrow section at aft, the engine have to be located in forward part of the engine room such that sufficient space is available on the side for maintenance. In case of container ships, the engine room is located near to midship. As the ship section is wider, smaller length of engine room is sufficient to accommodate the propulsion machinery with the auxiliaries. In oil tankers and gas carriers, the fuel tanks are also located within the engine room. While in container ships, the fuel oil tanks are located away from the engine room. 


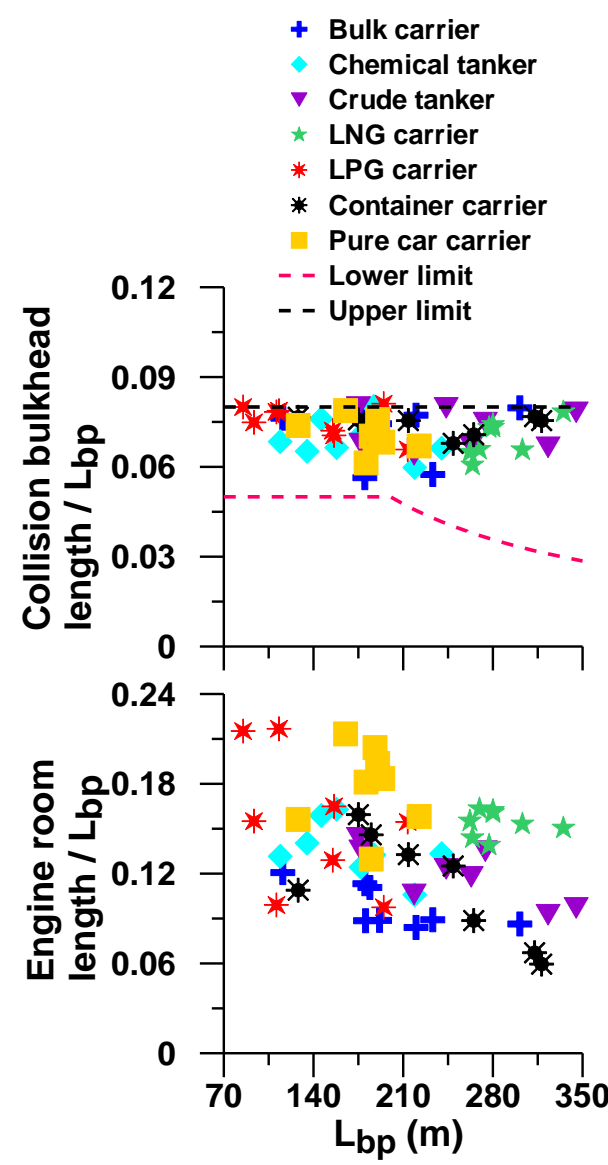

Fig. 4 Variation of collision bulkhead length and engine room length with length for different ship types.

The weight estimation at primary stage is an early milestone of ship design. Also, the accuracy and centroid of different components are vital to calculate the limiting $\overline{K G}$. On the other hand, inaccuracy has a substantial influence on the capacity, speed, and stability of the ship. Therefore, in the general arrangement design, we must give importance to calculation of hull, machinery and outfit weight. The ship's displacement can be estimated more accurately by estimating various weight components that constitute the displacement. This requires information from similar ships for different designs. There are different methods available for the estimation of steel weight of ships. The modern ships are usually lighter than older ones for the same capacity. However, for tankers stringent safety regulations MARPOL and OPA90 [14] has resulted in double hull construction resulting in increased steel weight. We assumed that mild steel is used as shipbuilding materials. In recent years, ships are built with some percentage (30\% to $59 \%$ ) of high tensile steel, to lower lightship weight and increase the cargo carrying capacity. Different lightship weight components are calculated by using the semi-empirical formulas proposed by D'Almeida [15]. The lightship weight is considered to be the sum of three main components:

$$
\mathbf{W}_{\mathrm{LS}}=\mathbf{W}_{\mathrm{ST}}+\mathbf{W}_{\mathrm{OT}}+\mathbf{W}_{\mathrm{ME}}
$$

The hull weight, superstructure, machinery weight, and outfit weight are estimated in the initial stage of design process. Besides above, the lightship weight $\left(\mathbf{W}_{\mathbf{L S}}\right)$ also includes lubrication oil, cooling water, feed water (boilers). Steel weight includes the weight of main hull, bed plates of machinery, etc. Accommodation weight includes the weight of superstructure and deckhouses. This also includes the weight for the improved quality of accommodation spaces, sanitary facilities, and air-conditioning besides regulatory requirements. To comply with regulatory requirements for temperature and noise, larger 
quantity of insulation materials is used in the engine room and accommodation. Generally, an increase of ship's length leads to a simultaneous increase of cargo carrying capacity, and steel weight. From Fig. 5, it is evident that an increase of length leads to linear increment in the steel weight. Outfit weight includes the weight of all fittings to the "naked" ship and detachable fitting on hull [16]. Recently, there is an increase in outfit weight due to higher quality of weather tight hatch covers, cranes and windlass/ mooring winches, deck machinery, firefighting equipment, etc. From Fig. 5, it appears that an increase of outfit weight is primarily governed by the ship's length. From Fig. 5, it is noticed that container ship has the maximum outfit weight. The reason is container ships have large longitudinal profile area above the waterline. It is common to accommodate containers on top of the main deck. Moreover, the containers have to be mandatorily secured by lashing equipment. Typical weight of lashing equipment is $0.024 \mathrm{t} / \mathrm{TEU}$ and $0.031 \mathrm{t} / \mathrm{FEU}$ container [1]. The fundamental component of machinery weight is the main engine, which depends on the speed and power requirement of different ships [17]. An increase of Froude number indicates an increased machinery weight and increased values of weight coefficients $\left(\mathrm{W}_{\mathrm{LS}} / \Delta\right)$ and $\left(\mathrm{W}_{\mathrm{LS}} / L B D\right)$ [1]. Besides above, machinery weight is also influenced by the type of ship and the position of the propulsion machinery (shaft length) and power demand for auxiliary machineries (pumps, separators, refrigeration etc.) [18].

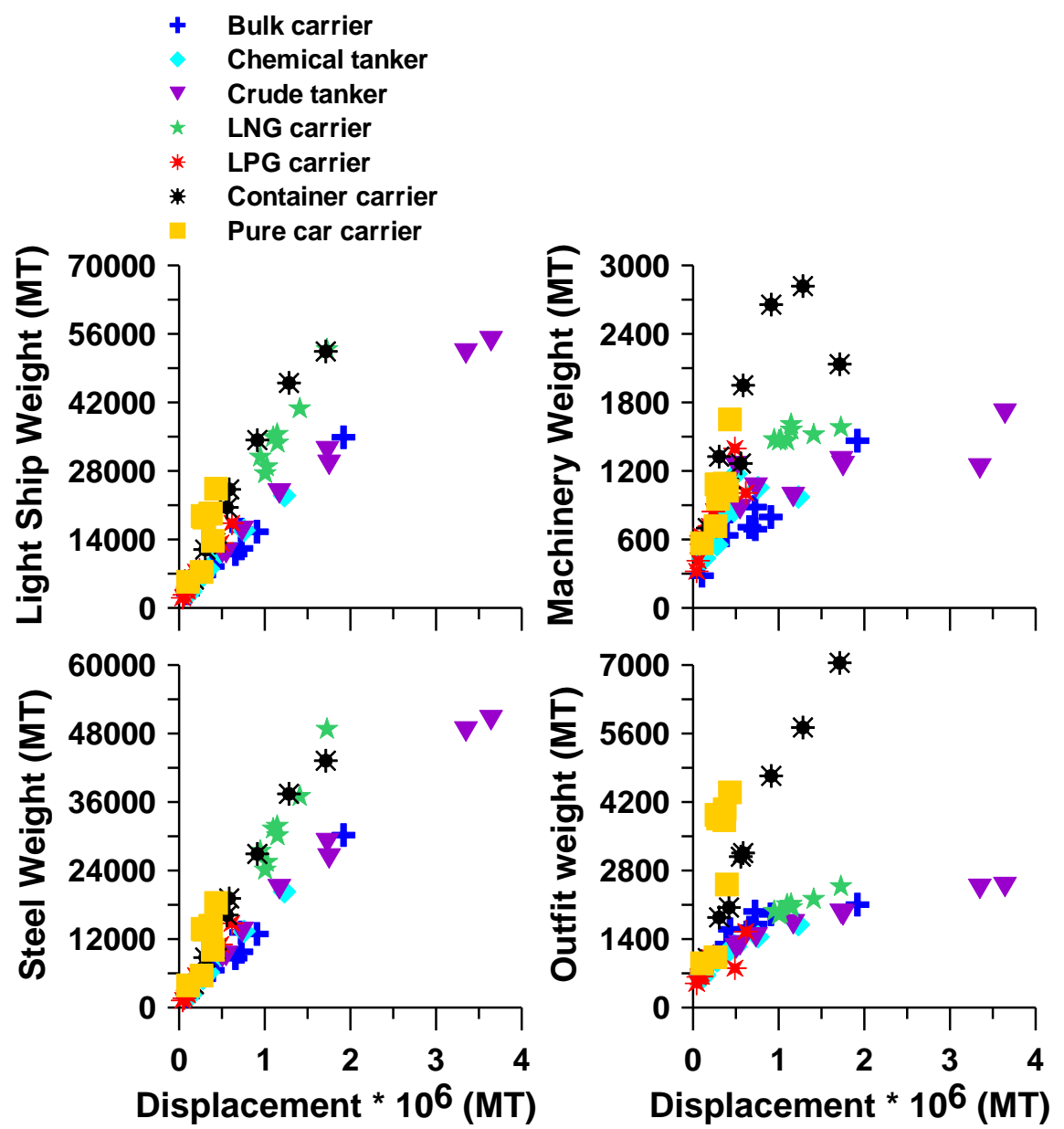

Fig. 5 Variation of different components of lightship weight with displacement for different ship types.

The propulsion machinery can be categorized into three different types like, two stroke diesel engine, four stroke diesel engine and steam turbine. The four stroke main engine and 
steam turbine must be coupled with reduction gear or with the accessories of controllable pitch propeller. If the propulsion machinery is steam turbine, the ship needs the main boiler to produce steam at high pressure. Some types of ships, container ship (refrigerated container), LNG and LPG carriers require a high demand for electrical energy for operating the refrigeration units. Finally, position of the engine room. In container ship it is located just aft of midship. This implies ship must have a lengthy propeller shaft to connect the propulsion machinery and the propeller. After identifying all elements which contribute to the machinery weight, it is evident from Fig. 5 that machinery weights of container ship are higher when compared with tanker and bulk carrier. Tanker vessels and bulk carriers have low Froude number that therefore required lower power of the main engine. On the other hand, container ships have high Froude number $(F r, \geq 0.25)$, low $C_{\mathrm{P}}, C_{\mathrm{B}}$ and high slenderness coefficient. This is because wave resistance is significant proportion to the total resistance. The container ships require high-speed as it carries perishable cargo in large volume which must reach the port at scheduled time. Therefore, containerships have relatively high engine power. It is evident from Fig. 6 that container ship has higher main engine power, even though their dead weights are low. This leads to an increase of the main machinery, and auxiliary machinery weight. The auxiliary machineries are supporting the operation of main machinery (pumps, separators, boiler etc.).

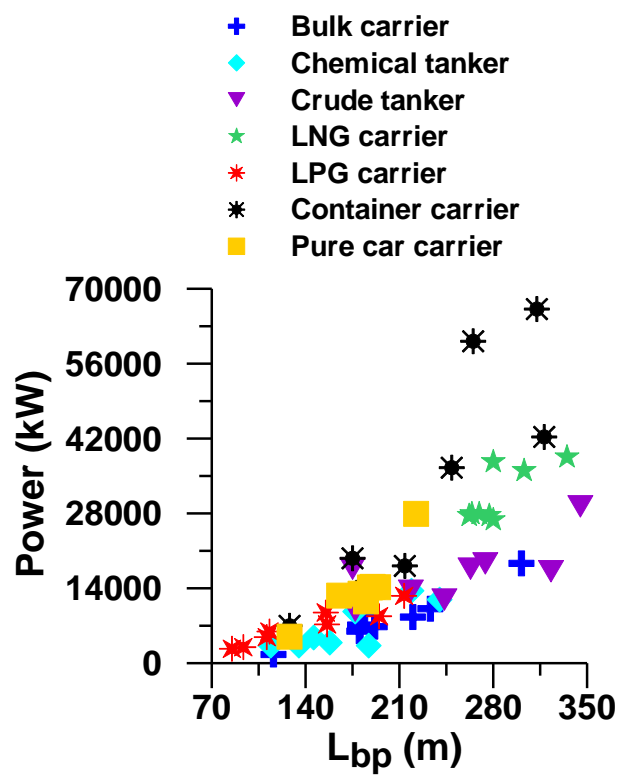

Fig. 6 Variation of different main engine power with length for different ship types.

The ballast water capacity is an important element to operate ship safely at sea. The ballast water capacity is an important feature for both volumetric and dead weight carriers. In the ballast voyage, ships must satisfy safety requirements like minimum mean draft and forward draft, maximum permissible trim, and sufficient propeller immersion. Also the ship shall not trim by bow in loaded departure condition. Therefore, all the ships require a sufficient amount of ballast to satisfy the above mentioned safety requirements. The capacity of the ballast tanks shall be determined as described in Table 3 (MARPOL Regulation 18 [14]). The ballast tanks are placed along the ship's sides or wing, double bottom, fore and aft depending on the type of vessel. In tanker vessel, the whole cargo tank should be protected by double bottom and side ballast tanks. The side and bottom tank width and height have to comply with the requirements of MARPOL to avoid the pollution at the time of collision or grounding [14]. 
Table 3 Criteria for ballast draft condition applied to all ships

\begin{tabular}{|l|l|l|}
\hline Sr. no. & Requirements & \multirow{2}{*}{ Rules } \\
\hline 1. & Trim $\leq=0.015^{*} L_{\mathrm{bp}}$ & \\
\cline { 1 - 2 } 2. & Mean draft $\geq\left(2.0+0.02 L_{b p}\right)$ & \multirow{2}{*}{ MARPOL } \\
\cline { 1 - 2 } 3. & $\begin{array}{l}\text { Full propeller immersion in sailing } \\
\text { condition }\end{array}$ & \multirow{2}{*}{ Classification rule } \\
\hline 4. & Forward draft $\geq 0.04 * L_{\mathrm{bp}}$ & \\
\hline
\end{tabular}

Figure 7 illustrates that volumetric carriers require relatively low ballast water capacity to achieve the safety requirement as the design draft is less as compared with deadweight carrier. On the other hand, tankers and bulk carriers have relatively high $C_{\mathrm{P}}, C_{\mathrm{B}}$ and $C_{\mathrm{M}}$ coefficients as shown in Fig. 2 and also, the design draft are relatively high for dead weight carriers. As a result from Fig. 7, it is obvious that dead weight carriers require higher volume of ballast water to ensure safety of vessel (MARPOL Regulation 18 [14]). It is evident from the previous discussions that crude oil tankers and bulk carriers have comparatively smaller $L / B$, high $L / D$ ratio with high $C_{\mathrm{P}}$ and $C_{\mathrm{B}}$ resulting in high cargo carrying capacity as seen in Fig. 7.

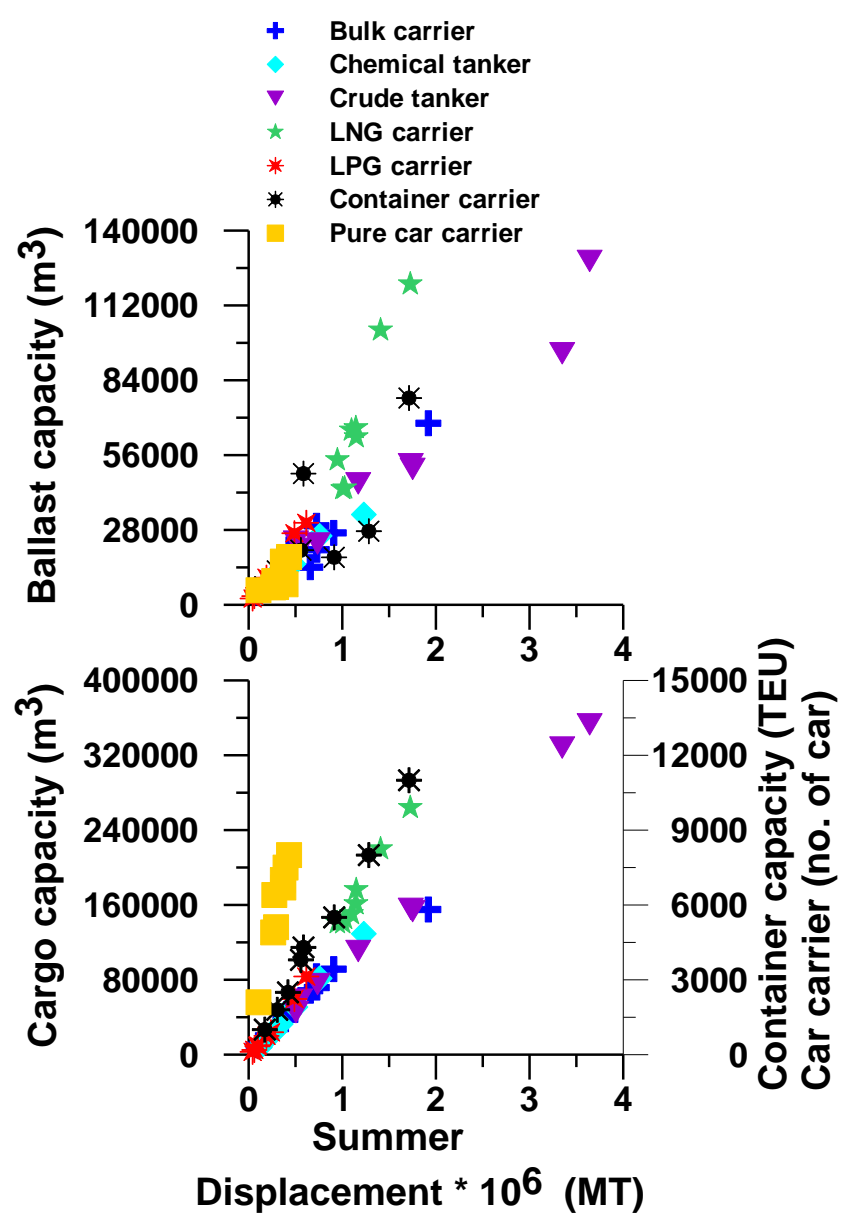

Fig. 7 Variation of ballast and cargo capacity with displacement for different ship types. 


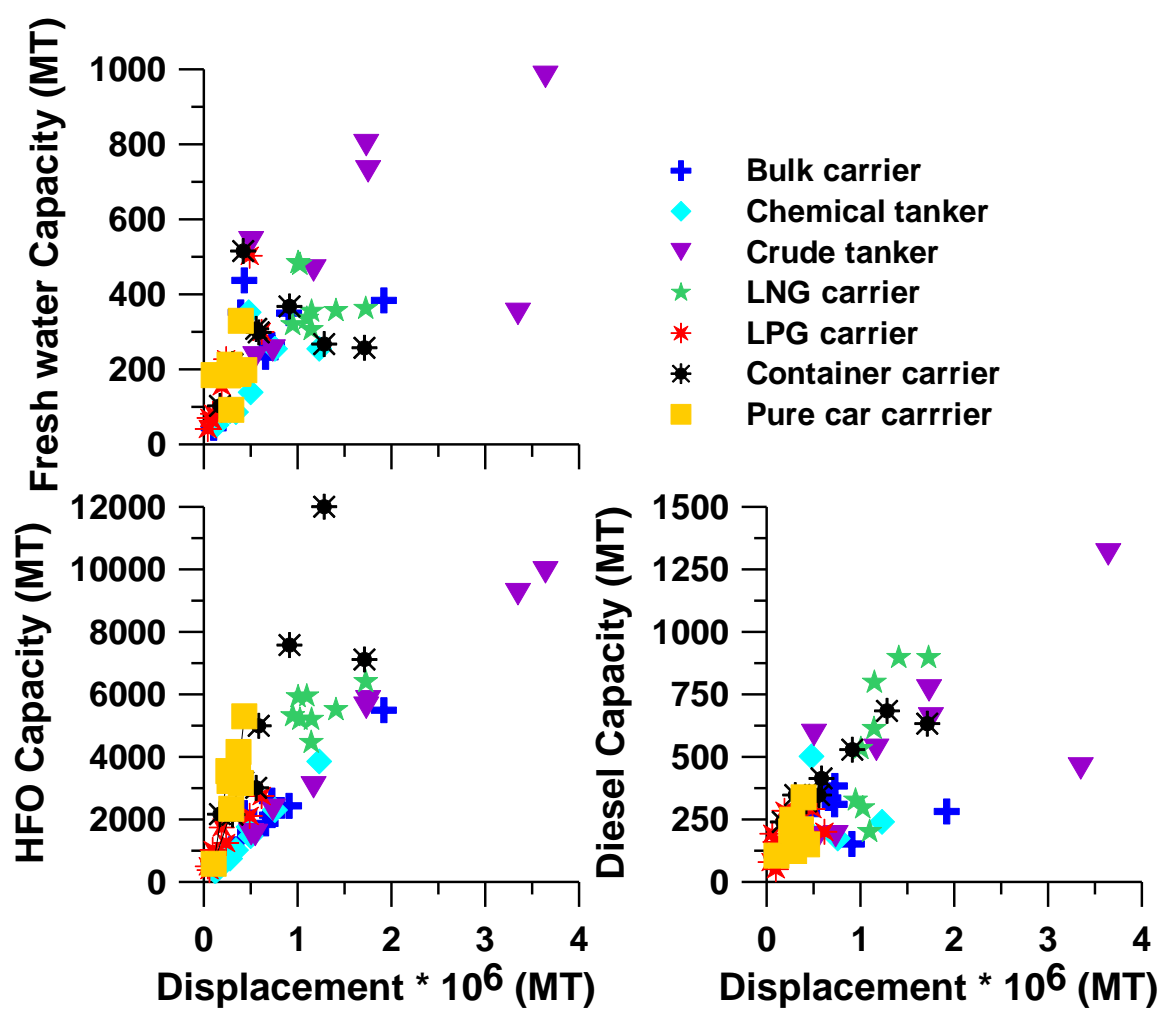

Fig. 8 Variation of HFO, diesel oil and fresh water capacity with displacement for different ship types.

As discussed before, deadweight includes the machinery supplies like heavy fuel oil (HFO), diesel oil and fresh water. The cooling water for machinery and feed water of boilers constitute part of lightship weight. HFO is used as fuel in main engine, boilers and auxiliary engine. A significant quantity of HFO is consumed by the main engine. The consumption of HFO depends on the main engine power (Fig. 6) and specific fuel consumption. Figure 8 shows that tanker and container ships require large volume of HFO. Also, the HFO carrying capacity is relatively larger for container ships as compared to other ships, because in every voyage bunkering cannot be afforded to decrease the turn-around time of the ship. Similarly, liquefied gas carriers require refrigeration facilities to maintain the temperature $\left(-55^{\circ} \mathrm{C} \sim-163\right.$ ${ }^{\circ} \mathrm{C}$ ) in cargo tanks. Therefore, LNG carriers have higher HFO consumption as shown in Fig. 8. In the case of consumption of diesel, the crude oil tanker required relatively large volume diesel for the inert gas generation unit. Inert gases are pumped into cargo tanks to prevent the fire hazard. From Fig. 8, one can conclude that tankers require large volume of diesel oil. MARPOL regulation [19] is followed for double hull protection of fuel oil tanks on all type of ships. Individual oil fuel tanks capacity is kept less $2,500 \mathrm{~m}^{3}$ for compliance with the MARPOL regulations [19]. As discussed before, steam is used for different application like preheating of crude and fuel, and cleaning. From Fig. 8, it is evident that the tankers require relatively high volume of fresh water as boiler feed water. On the other hand, for LNG carriers, steam turbines are used as the main propulsion machinery. In LNG carriers, steam is used in main turbine and auxiliary preheating services. They use the boil off-gases from the cargo to reduce the fuel consumption of the main boiler. However, they require a significant quantity of fresh water, to produce steam for running turbines. For all ships, fresh water tanks capacity and location were based on parent ship arrangements.

Design considerations for oil tanker will be discussed. The present analysis consists of 17 different tanker ship designs. The design for the oil tanker is very elaborate and based on 
compliance with MARPOL regulations. For oil tankers the following MARPOL regulations (Annex 1) influence the general arrangement design:

(i) Regulation 18, It specifies the minimum draft and maximum permissible trim during ballast condition.

(ii) Regulation 19, Double hull and double bottom requirements: It specifies the minimum width and height of the double side and double bottom in way of the cargo, slop tanks and pump room. The objective is to avoid pollution at the time of collision or grounding.

(iii) Regulation 23, Accidental oil outflow performance: It is based on probabilistic concept. It specifies a limit on the amount of oil outflow from the tank in case of damage. The deepest load line draft is taken as the design draft and the minimum tide is considered as $-2.5 \mathrm{~m}$ (low tide). It is assumed that after collision, all cargo in the damaged cargo tanks are spilled out. Some reduction in oil spillage is given in case of double hull tanks.

(iv) Regulation 28, Subdivision and damage stability: It is based on deterministic concept. It specifies the damage stability requirements to be complied by the vessel in case of damage. It is assumed that all the liquid cargo in the damaged cargo tanks are spilled out.

(v) Regulation 29, It specifies the minimum capacity of the slop tanks.

All the ship designs investigated in this paper are assessed to sustain the damage extent requirement [20] and to fulfill the damage stability requirements as shown in Table 4.

Table 4 Various criteria requirements for intact and damage condition to all type of ships

\begin{tabular}{|c|c|c|c|c|}
\hline Sr. no. & Ship type & $\begin{array}{l}\text { Intact stability } \\
\text { criteria }\end{array}$ & $\begin{array}{l}\text { Damage stability } \\
\text { criteria }\end{array}$ & Damage analysis \\
\hline 1. & Bulk carrier & IMO MSC.23(59) & IMO MSC.216 (82) & $\begin{array}{l}\text { Probabilistic } \\
\text { method }\end{array}$ \\
\hline 2. & Car carrier & IMO A.749 (18) & IMO MSC.216 (82) & $\begin{array}{l}\text { Probabilistic } \\
\text { method }\end{array}$ \\
\hline 3. & Container & IMO A.749 (18) & IMO MSC.216 (82) & $\begin{array}{l}\text { Probabilistic } \\
\text { method }\end{array}$ \\
\hline 4. & LNG carrier & IGC code & IGC code & $\begin{array}{l}\text { Deterministic } \\
\text { method }\end{array}$ \\
\hline 5. & LPG carrier & IGC code & IGC code & $\begin{array}{l}\text { Deterministic } \\
\text { method }\end{array}$ \\
\hline & & MARPOL & MARPOL & $\begin{array}{l}\text { Deterministic } \\
\text { method }\end{array}$ \\
\hline 6. & Tankers & $\begin{array}{l}\text { Accidental oil } \\
\text { outflow }\end{array}$ & $\begin{array}{l}\text { Accidental oil } \\
\text { outflow }\end{array}$ & $\begin{array}{l}\text { Probabilistic } \\
\text { method }\end{array}$ \\
\hline
\end{tabular}

The accidental oil outflow in different damage scenario is shown in Fig. 9. The mean oil outflow is calculated independently for side and bottom damage and then combined into non-dimensional oil outflow parameter $\mathrm{O}_{\mathrm{M}}$ as shown in Fig. 9. Figure 9 shows that the spilled volume varies depending on the side or bottom damage. The estimated oil outflow from the side damage is higher as compared to bottom damage. The tank's bottom plate experience higher hydrostatic pressure as compared to the side tank plates. Therefore, the bottom oil outflow is lower as compared with the side oil outflow. It is observed from Fig. 9 that the mean outflow gradually reduces with increasing cargo capacity. 


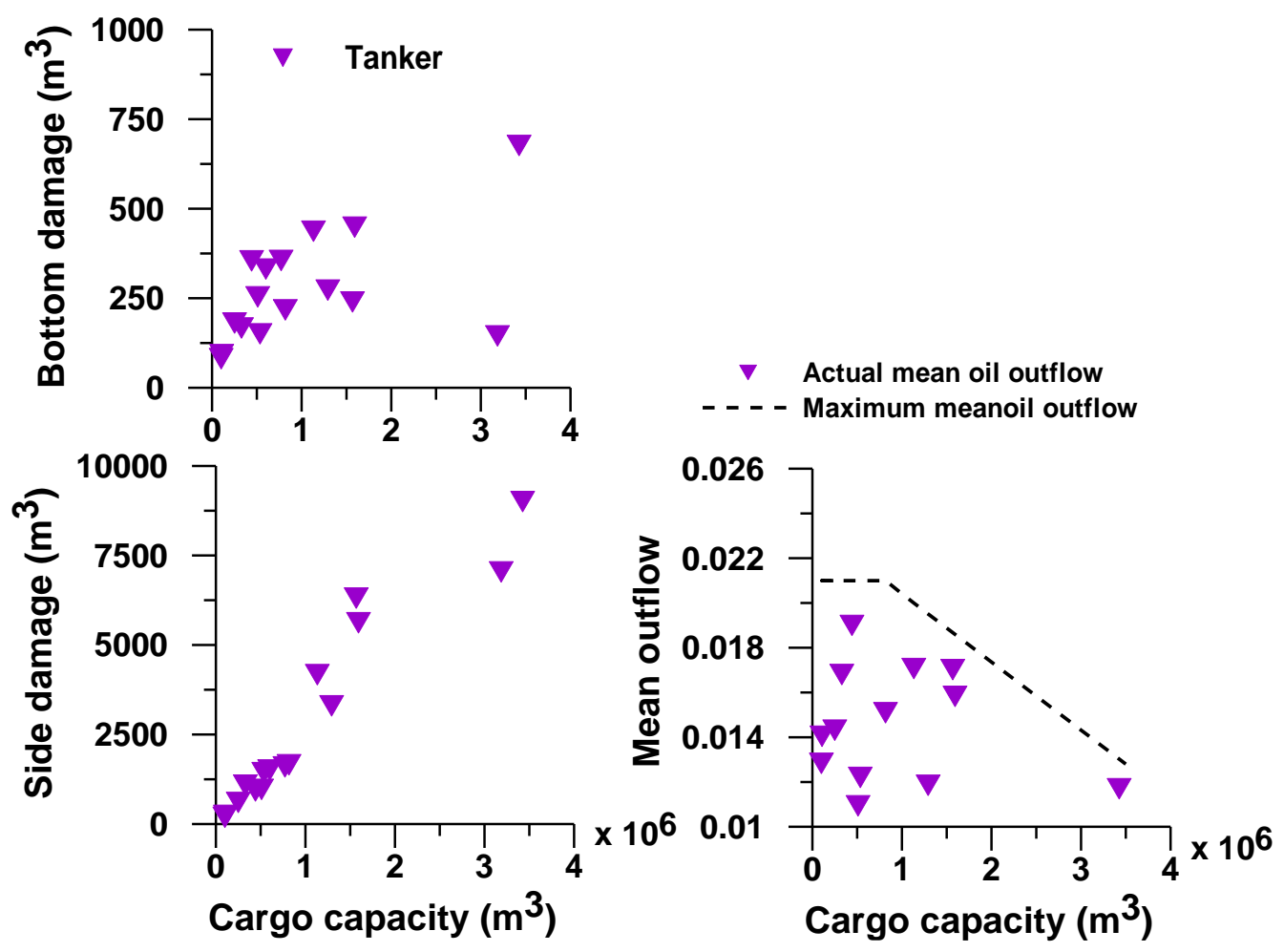

Fig. 9 Variation of accidental oil outflow with cargo capacity for different tanker ships.

Design considerations for gas carriers will be discussed. For gas carriers general arrangement design is based on the requirements of International Gas Carrier (IGC) code [21]. The design requirements depend on the type of cargo. The gas carrier ships investigated in this paper are designed for carrying cargo suitable for "Type $2 \mathrm{G} / 2 \mathrm{PG}$ " ships. The ships are mainly intended for carrying LPG, LNG, ammonia and ethane. Even for Type 2G/ 2PG ships, the design requirements depend on the cargo carrying temperature. If the cargo temperature is less than $-55^{\circ} \mathrm{C}$, a continuous side longitudinal bulkhead in way of cargo tanks is provided. If the cargo temperature is between $-10{ }^{\circ} \mathrm{C}$ and $-55^{\circ} \mathrm{C}$, only double bottom is provided. For all cases, there shall be minimum $0.76 \mathrm{~m}$ clearance between the tank and the ship's shell plate. The refrigerated cargo tanks must be insulated to maintain the temperature of the cargo tank and prevent boil-off. The insulated independent tanks are located in hold space. In case of independent tanks, minimum spacing must be provided between the insulation and the ship structure to permit passage of personnel for inspection. In case of membrane tanks, when insulation is applied on one side of the main hull structure, the other side shall be always accessible for inspection. Therefore, for membrane type LNG ships, between two cargo tanks, void space/ cofferdam shall be provided. Similarly sufficient size of opening must be provided on horizontal and vertical structural members for taking out injured personnel strapped on stretcher from the cargo/ ballast tank spaces. Therefore, the gap between the cargo tank and the main hull and depth and width of the double bottom and double side spaces shall be carefully designed [21]. In this paper all LPG carriers have independent self supporting tanks. For LNG carriers, both independent self supporting tank and membrane type tank designs are considered. In LNG carriers, there are some differences between the layout of independent type tank and membrane type tank design. In case of independent type tank design, a number of large diameter spherical tanks are placed along the ship's length. The spherical tank diameter depends on ship's beam. Each one of the spherical tank, is insulated from outside. The hold space supporting the spherical tank is covered by weathertight steel plate. In membrane type design, void space is provided between transverse bulkheads on which the membrane type insulation is applied. On the deck, void space is 
provided above the cargo tank for compliance with regulation. Therefore, length and beam are an important factor to attain the cargo capacity of LPG/ LNG carrier. For both the LPG and LNG ships, water ballast tanks, configuration is provided as per parent ship design configuration. There are some differences in the deterministic damage stability calculations for oil tankers and gas carriers as described in Table 5. This will influence the limiting $K G_{\mathrm{LS}}$ and $L C G_{\mathrm{LS}}$ characteristics of these ship types.

Table 5 Difference between the damage stability requirements of oil tanker and liquid gas carrier

\begin{tabular}{|c|l|l|}
\hline Sr. no. & Oil tankers & Gas carriers \\
\hline 1 & $\begin{array}{l}\text { Tankers of more than } 225 \mathrm{~m} \text { in length } \\
\text { should be assumed to sustain damage } \\
\text { anywhere in its length. }\end{array}$ & $\begin{array}{l}\text { A type } 2 \mathrm{G} \text { ship of more than } 150 \mathrm{~m} \text { in } \\
\text { length should be assumed to sustain } \\
\text { damage anywhere in its length. }\end{array}$ \\
\hline 2 & $\begin{array}{l}\text { Oil tankers } 20,000 \text { tonnes deadweight } \\
\text { and above, shall be able to sustain } \\
\text { bottom raking damage. }\end{array}$ & $\begin{array}{l}\text { Not applicable. } \\
\text { The angle of heel due to } \\
\text { unsymmetrical flooding shall not } \\
\text { exceed } 25^{\circ} . \text { This angle may be } \\
\text { increased up to } 30^{\circ} \text { if no deck edge } \\
\text { immersion occurs. }\end{array}$ \\
\hline
\end{tabular}

Design considerations for bulk carrier will be described. The top side tanks were designed based on angle of repose. The bottom hopper tanks were designed based on parent ship configuration. Most of the bulk carriers are single hull construction. The common design feature of the ship is to achieve maximum volume in cargo holds to accommodate maximum cargo quantity, up to the maximum allowable draft. Bulk ore carriers are designed for "alternate hold loading" condition for stability and motion considerations. This means the cargo can be loaded in "alternate holds" i.e. odd number (1, 3, and 5) of holds. This loading pattern significantly increases the shear force and bending moment on the ship. It also requires extra strengthening of the tank top plating in order to endure higher cargo loading. Their longitudinal strength need to be investigated in detail for this purpose.

For PCC ships ballast capacity is checked for minimum sailing draft requirements. The freeboard deck is fixed based on the cargo loading / unloading ramp location. The numbers of transverse bulkheads are kept to a minimum for ease of loading / unloading cargo. Above the freeboard deck, several decks are provided for storing the cargo. However these deck are non watertight and do not contribute to either reserve buoyancy or structural strength. For some container ships, the accommodation is located in the forward side. The cargo holds are also provided at aft. The cargo hold lengths were based on standard container sizes. Transverse non watertight bulkheads were provided based on parent ship design. The side tanks boundaries were made vertical and sizes were compatible with the standard container dimensions. Container ships during some voyages may carry less number of loaded containers onboard and significant amount of empty containers may be carried on top two tiers of deck. This can cause a rise in $\overline{K G}$ of ship. To make sure that the ship has adequate $\overline{\mathrm{GM}} \mathrm{T}$, ballast water may be carried in the partially loaded condition. In practice, each ship type may experience different loading condition. Due to this the vessel may trim based on the $L_{\mathrm{CG}}$ position. In all the loading condition, it is preferred to have trim by aft. 


\section{Method of analysis}

In this section, the analysis methodology will be described as shown in Fig. 10. The analysis is carried out in 2 steps. First, the limiting $L C G_{\mathrm{LS}}$ and $K G_{\mathrm{LS}}$ is determined using intact stability rules. Thereafter, further restrictions are imposed on $L C G_{\mathrm{LS}}$ and $K G_{\mathrm{LS}}$ based on damage stability requirements.

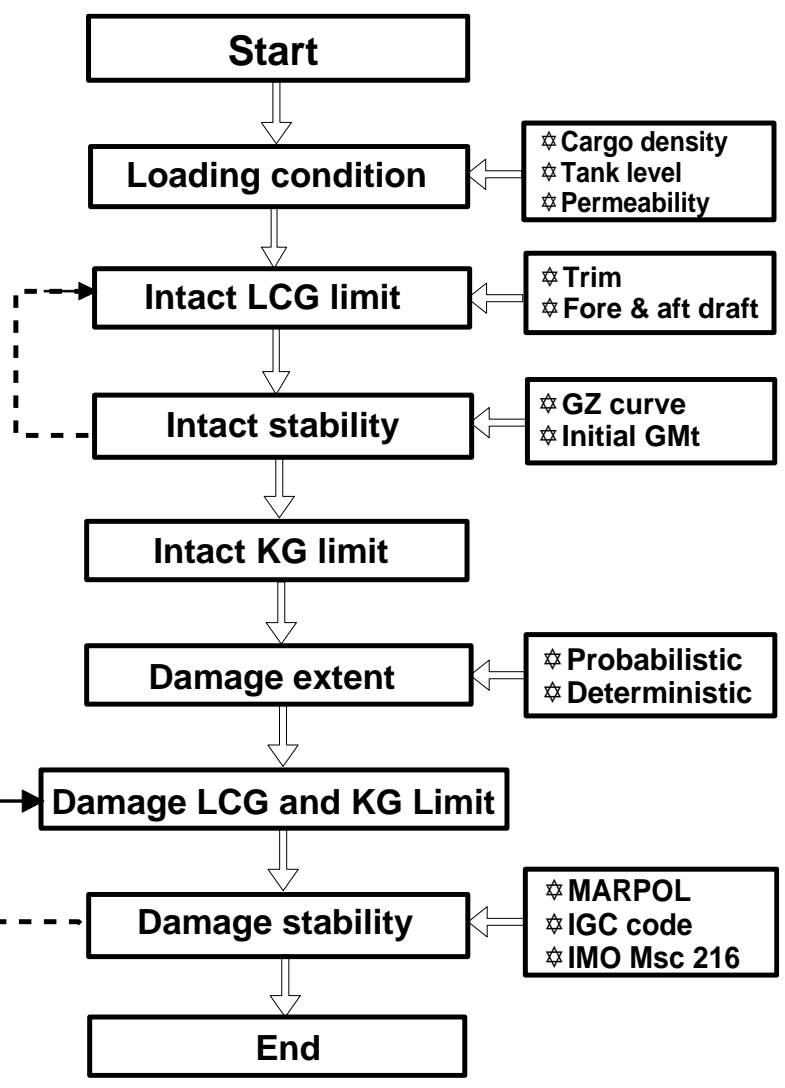

Fig. 10 Iterative procedure of estimation of lightship $L C G_{\mathrm{LS}}$ and $K G_{\mathrm{LS}}$ of various ships

First, intact stability analysis will be described. Different intact stability loading conditions namely, "loaded departure condition", "loaded arrival condition", "ballast departure condition" and "ballast arrival condition" specified in the regulations are developed for each ship type [13] and the intact stability criteria requirement shown in Table 6. For oil tankers and gas carriers in "loaded departure condition", the cargo holds are filled up to $98 \%$ and fuel oil, diesel oil, fresh water are filled up to $95 \%$ of full capacity. In "loaded arrival condition" the fuel oil, diesel oil and fresh water are assumed to be consumed $85 \%$ of full capacity in transit and the cargo quantity remains as $98 \%$. For LNG carrier $0.2 \%$ boil off is assumed. In case of bulk carriers, for the "loaded departure condition", the cargo holds are loaded for "uniform" and "alternate hold" loading condition respectively. 
Table 6 Criteria requirements for intact condition to all type of ships

\begin{tabular}{|l|l|l|l|}
\hline Sr.no. & Criteria & Value & Criteria \\
\hline 1. & $\int_{0}^{30^{\circ}} \overline{G Z} d \phi$ & $\geq 3.1513 \mathrm{~m} . \mathrm{deg}$ & $\begin{array}{l}\text { IMO intact stability } \\
\text { requirements [3] }\end{array}$ \\
\hline 2. & $\int_{0}^{40^{\circ}} \overline{G Z} d \phi$ & $\geq 5.1566 \mathrm{~m} . \mathrm{deg}$ & $\begin{array}{l}\text { IMO intact stability } \\
\text { requirements [3] }\end{array}$ \\
\hline 3. & $\int_{30^{\circ}}^{40^{\circ}} \overline{G Z} d \phi$ & $\geq 1.7189 \mathrm{~m} . \mathrm{deg}$ & \\
\hline 4. & Minimum $\overline{G Z}$ & $\geq 0.2 \mathrm{~m}$ & \\
\hline 5. & Maximum $\overline{G Z}$ should occur at $\phi$ & $\geq 25^{\circ}$ & \\
\hline 6. & Initial $\overline{G M_{T}}$ & $\geq 0.15 \mathrm{~m}$ & \\
\hline
\end{tabular}

In case of container ships, the average weight of containers (14 tonnes) in the cargo hold and deck is considered to achieve the desired draft for the "loaded departure condition". In case of PCC ship, the loading of cars is carried out in the hold to achieve the desired draft for the "loaded departure condition". For all the ships, ballast tanks are suitably filled up to comply with the regulations for "ballast departure condition". For bulk carriers, container ships and PCC ships, loading of fuel oil, fresh water is carried out in the same manner as for the oil tankers and gas carriers. All the ships were loaded to respective ballast and loaded draft.

For oil tankers and gas carriers, the additional "in port" operating condition was checked. During this condition, the cargo tanks are unloaded and the ballast tanks are loaded simultaneously. There will be a situation where all the cargo and ballast tanks are slack simultaneously. This will increase the free surface effect. In this condition, it must be ensured that $\overline{G M_{T}} \geq 0.15 \mathrm{~m}$.

(1) In "ballast departure condition", the cargo tanks/ holds are empty. The ballast tanks, fuel oil, diesel oil and fresh water tanks are filled up to $95 \%$ of full capacity. The tank capacities and arrangement are so designed that the ballast draft satisfies full propeller immersion, minimum trim by aft, minimum mean draft and minimum draft at forward to prevent slamming. The conditions are described in Table 3. In ballast arrival condition at the port the fuel oil, diesel oil, fresh water tank quantity was consumed to $50 \%$ or $15 \%$ of full capacity. For some ships leftover of $15 \%$ of fuel is unlikely due to large HFO capacity.

(2) The limiting $K G_{\mathrm{LS}}$ at any desired draft is determined for complying with the intact stability condition as shown in Eq. 1 and other rules are described in Table 6.

$$
\begin{aligned}
& \int_{0}^{30^{\circ}} \overline{G Z} d \phi>=3.1513 \text { m.deg } \\
& \int_{0}^{30^{\circ}}\left(K N-\overline{K G_{1}} \sin \phi\right) d \phi>=3.1513 \text { m.deg }
\end{aligned}
$$




$$
\begin{gathered}
\overline{K G_{1}} \leq \frac{\left(\int_{0}^{30^{0}} K N d \phi\right)-3.1513}{\int_{0}^{30^{0}} \sin \phi d \phi} \\
\overline{K G_{\operatorname{Max}}} \leq \operatorname{Min}\left(\overline{K G_{1}}, \overline{K G_{2}}, \overline{K G_{3}}, \overline{K G_{4}}, \overline{K G_{5}}\right)
\end{gathered}
$$

Here $\overline{K G_{1}}, \overline{K G_{2}}, \overline{K G_{3}}, \overline{K G_{4}}$ and $\overline{K G_{5}}$ are the limiting $\overline{K G}$ 's corresponding to each rule requirement for a particular loading condition. In Eq. 1d, $\overline{K G_{M a x}}$ corresponds to each one of the loaded condition. The $K G_{\mathrm{LS}}$ can be calculated for each loading condition as shown in Eq. 2. The weight and $\overline{K G}$ of individual components like cargo, ballast, fuel and fresh water were determined as per the geometry of each hold/ tank.

$$
K G_{\mathrm{LS}} \leq \frac{\left(\Delta * \overline{K G_{\text {Max }}}\right)-\sum_{i=1}^{N}\left(\text { Weight }_{i} * \overline{K G_{i}}\right)}{W_{L S}}
$$

From Eq. 2, $K G_{\mathrm{LS}}$ is determined for several ship loading conditions. The minimum $K G_{\mathrm{LS}}$ from all the displacement conditions is the global maximum as it will satisfy all the limiting equations. In this numerical computation process, approximate values of $K G_{\mathrm{LS}}$ and $L C G_{\mathrm{LS}}$ are required as input. The $L C G_{\mathrm{LS}}$ corresponding to maximum permissible trim by aft is given as the input. The $K G_{\mathrm{LS}}$ calculated as per Schneekluth's method [2] is given as input.

(3) The limiting $L_{\mathrm{CG}}$ at any desired draft is determined for complying with the intact stability condition as shown in Eq. 3.

$$
0 \leq \frac{\Delta\left(L_{\mathrm{CB}}-L_{\mathrm{CG}}\right)}{M_{\mathrm{TC}}} \leq 0.015 L_{\mathrm{bp}}
$$

As per Eq. 3, the vessel is not permitted to trim by forward in any sailing condition. For some arrival conditions, due to consumption of fuel oil and fresh water, the vessel may trim by forward. Ballast water is taken on board to make the trim by forward equal to $0 \mathrm{~m}$. From Eq. 3 , it can be observed that ship's $L_{\mathrm{CG}}$ have an aft and forward limit. The limiting range of $L C G_{\mathrm{LS}}$, for each loading condition, can be obtained by logically modifying Eq. 3. The range of $L C G_{\mathrm{LS}}$ which satisfies all the loading condition will be the acceptable range of $L C G_{\mathrm{LS}}$ for the ship type investigated. For the selected range of $L C G_{L S}$, all intact stability requirements described in Table 6 will be complied with. In this numerical computation process, the values of $K G_{\mathrm{LS}}$ and $L C G_{\mathrm{LS}}$ are required as input. The $L C G_{\mathrm{LS}}$ corresponding to maximum permissible trim by aft is given as the input. The $K G_{\mathrm{LS}}$ calculated as per Schneekluth's method [2] is given as input.

The $K G_{\mathrm{LS}}$ and $L C G_{\mathrm{LS}}$ limits determined earlier are now checked for compliance with the damage stability requirements. During damage stability calculations it is implicitly 
assumed that the lightship weight, $K G_{\mathrm{LS}}$ and $L C G_{\mathrm{LS}}$ do not change after the damage. This could be unlikely during heavy damage. However, for the purpose of determining limiting $L C G_{\mathrm{LS}}$ and $K G_{\mathrm{LS}}$, this assumption needs to be made. First the computations for deterministic damage stability will be described. This is applicable for oil tankers, gas carriers and ships complying with damage stability rules of load line regulations. During asymmetric damage, the inferior part of the $\overline{G Z}_{\text {Damaged }}$ curve is considered for compliance with rules. The following damage cases are checked:

(1) The longitudinal, transverse and vertical extent of damage is applied as specified in MARPOL [14], IGC [21] and Loadline rules [13]. Single/ multiple compartment damage for cargo area and engine room is applied as per rules.

(2) When a loaded tank is damaged, the liquid inside the tank (cargo or fuel or freshwater) is assumed to be lost from the damaged tank. In this case the displacement and centre of gravity of the ship before and after the damage will be different.

(3) When a loaded cargo hold is damaged, its permeability is considered for damage stability as per rules. For example, in case of bulk carrier, PCCs and container ships, the entire hold cannot be flooded with water due to the presence of cargo. The permeability values used for damage stability calculation are described in Table 7 [3].

(4) For double bottom/ double side ships, in the loaded condition, the damage to only outer hull is also checked. In this case, usually there is no change in the displacement or the centre of gravity of the ship. This is because double hull spaces are empty during loaded condition. This includes the "bottom raking damage" for oil tankers. Here, the outer hull is damaged to a length, as specified in the rules due to grounding. This damage condition imposes strict requirement on the water ballast tank design configuration. The "bottom raking damage" is applied only for the oil tankers (MARPOL rule requirement) and not the gas carriers. Also, the permeability of a tank containing liquids is assumed that the contents are completely lost from that tank and replaced by water.

Table 7 Permeability of different tanks and compartment of ships

\begin{tabular}{|l|l|l|}
\hline Sr.no. & Space & Permeability \\
\hline 1 & Appropriated to stores & 0.60 \\
\hline 2 & Cargo liquids & 0.70 \\
\hline 3 & Container spaces & 0.70 \\
\hline 4 & Dry cargo space & 0.70 \\
\hline 5 & Ro-Ro spaces & 0.90 \\
\hline 6 & Occupied by accommodation & 0.95 \\
\hline 7 & Occupied by machinery & 0.85 \\
\hline 8 & Void spaces & 0.95 \\
\hline 9 & Consumable liquids & 0.95 \\
\hline
\end{tabular}

The damage stability requirements are different for oil tankers, gas carriers and general cargo ships. In case of oil tankers and gas carriers, the damage stability check is only done for loaded condition [14], [21]. The damage stability survival requirements are not applied to the ship in the ballast condition. All the tanker designs are assessed to sustain the damage requirement [20] to fulfil the damage stability requirements as shown in Table 4. The damage 
stability requirements for gas carriers were checked as per IGC code as described in Table 8 [21]. The procedure followed is same as that for oil tankers. The intact and damage criteria requirements are shown in Tables 6 and 8.

Table 8 Various criteria requirements for damage condition to all type of ships

\begin{tabular}{|c|l|l|l|l|}
\hline Sr. no. & Criteria & MARPOL & IGC code & IMO MSC. 216 (82) \\
\hline 1. & $\int_{\phi_{1}}^{\phi_{1}+20^{\circ}} \mathrm{GZ} d \phi$ & $\geq 1.002 \mathrm{~m} . \mathrm{deg}$ & $\geq 1.002 \mathrm{m.deg}$ & -- \\
\hline 2. & GZ & $\begin{array}{l}\text { at least } 0.1 \mathrm{~m} \\
\text { between } \phi_{1} \text { and } \phi_{1}+ \\
20^{\circ}\end{array}$ & $\begin{array}{l}\text { at least } 0.1 \mathrm{~m} \\
\text { between } \phi_{1} \text { and } \phi_{1}+\text { at least } 0.120 \mathrm{~m} \\
20^{\circ}\end{array}$ & $\geq 30^{\circ}$ \\
\hline 3. & $\begin{array}{l}\text { Maximum damage } \\
\text { permissible heel } \\
\text { angle after damage }\end{array}$ & $\geq 25^{\circ}$ & $\geq 30^{\circ}$ & \\
\hline
\end{tabular}

The limiting $K G_{\mathrm{LS}}$ at any desired damaged loading draft is determined for complying with the damage stability rules as shown in Eqs. 4 and 5.

$$
\begin{aligned}
& 0.0175 \text { m.rad } \leq \int_{\phi_{1}}^{\phi_{1}+20^{\circ}} \overline{G Z} \text { Damaged } d \phi \\
& 0.0175 \mathrm{~m} . \mathrm{rad} \leq \int_{\phi_{1}}^{\phi_{1}+20^{\circ}}(K N-\overline{K G} \sin \phi)_{\text {Damage }} d \phi \\
& \overline{K G}_{\text {Damage } 1} \leq \frac{\int_{\phi_{1}}^{\phi_{1}+20^{\circ}}(K N)_{\text {Damage }} d \phi-0.0175}{\int_{\phi_{1}}^{\phi_{1}+20^{\circ}} \sin \phi d \phi}
\end{aligned}
$$

$$
\begin{array}{ll}
0.1 \leq \operatorname{Max}\left(\overline{G Z}_{\text {Damage }}\right) & \text { for } \phi_{1} \leq \phi \leq \phi_{1}+20^{0} \\
0.1 \leq \operatorname{Max}\left(\mathrm{KN}_{\text {Damage }}\right)-\overline{K G}_{\text {Damage } 2} & \text { for } \phi_{1} \leq \phi \leq \phi_{1}+20^{0} \\
\overline{K G}_{\text {Damage } 2 \leq \operatorname{Max}\left(\mathrm{KN}_{\text {Damage }}\right)-0.1} & \text { for } \phi_{1} \leq \phi \leq \phi_{1}+20^{0}
\end{array}
$$$$
\left.\phi_{1} \leq \begin{array}{l}
25^{\circ}, \text { if deck immersion occurs } \\
30^{\circ} \text {, if no deck immersion }
\end{array}\right\} \text { for oil tankers }
$$

$\phi_{1} \leq 30^{\circ}$ for gas carriers

$$
\left(\overline{K G}_{\text {Damage }}\right)_{\mathrm{Max}} \leq \operatorname{Min}\left(\overline{K G}_{\text {Damage } 1,}, \overline{K G}_{\text {Damage } 2}\right)
$$


Here $\overline{K G}_{\text {Damage1 and }} \overline{K G}_{\text {Damage2 }}$ are the limiting $\overline{K G}_{\text {Damage corresponding to each rule }}$ requirement. In case of damage stability, it may be noted that for each loading condition there are several possible combination of damages. $(\overline{K G} \text { Damage })_{\mathrm{Max}}$ Corresponds to all possible damages for each loading condition. The limiting $K G_{\mathrm{LS}}$ can be calculated for each loading condition as shown in Eq. 6. The weight and $\overline{K G}$ of individual components like cargo, ballast and fuel were determined as per the exact geometry of the compartment. In case of oil tankers and gas carriers, the contents of the damaged tanks are assumed to be completely lost. In case of bulk carrier and container ships, permeability of the damaged cargo tank is considered.

$$
K G_{\mathrm{LS}} \leq \frac{\left(\Delta_{\text {Damage }} *(\overline{K G} \text { Damage })_{\text {Max }}\right)-\sum_{i=1}^{N}\left(\text { Weight }_{\mathrm{i}} * \overline{K G_{i}}\right)}{\mathrm{W}_{\mathrm{LS}}}
$$

From Eq. 6, $K G_{\mathrm{LS}}$ is determined from several damaged ship loading condition. The minimum $K G_{\mathrm{LS}}$ from the intact and damaged stability conditions is the global maximum as it will satisfy all the limiting equations. The $L C G_{\mathrm{LS}}$ value corresponding to maximum permissible trim by aft was used during the damage stability calculations for determining the limiting $K G_{\mathrm{LS}}$. The limiting $L_{\mathrm{CG}}$ at any desired draft is determined for complying with the damage stability condition as shown in Eq. 7.

$$
\operatorname{Trim}_{\text {Damage Forward }} \leq \frac{\Delta_{\text {Damage }}\left(L_{\mathrm{CB}}-L_{\mathrm{CG}}\right)_{\text {Damage }}}{\left(M_{\mathrm{TC}}\right)_{\text {Damage }}} \leq \operatorname{Trim}_{\text {Damage Aft }} \text { (7) }
$$

A ship is assumed to survive a damage condition if the final waterline, taking into account sinkage, heel and trim, is below the lower edge of any opening through which down flooding may take place. It is difficult to get a mathematical expression for $L_{\mathrm{CG}}$ using the ship geometric particulars from Eq. 7 as is done for $\overline{K G}$ from Eqs. 4 and 5. Therefore, an iterative method is followed in this paper for this purpose. The $L C G_{\mathrm{LS}}$ lower and upper limit determined from the intact stability conditions are used during the damage stability conditions. The number of damaged combinations for each loaded conditions is very high. The damage stability calculations are first carried out using the $L C G_{\mathrm{LS}}$ lower and upper limit. If all the damage stability rule requirements are satisfied, then the intact stability $L C G_{\mathrm{LS}}$ lower/ upper limits are retained. If not, the upper/ lower limit, as the case may be, is decremented by $0.01 L_{\mathrm{bp}} \%$ in steps and the damage stability calculations are repeated. The process is continued till the assumed $L C G_{\mathrm{LS}}$ upper/ lower limit meets all the damage stability requirements. It is ensured that the vessel remains in floating condition (with heel and trim) as per the requirements of MARPOL/ IGC for all the permissible damage cases. Therefore, the final limiting values specified would comply with both the intact and damage stability requirements as described in Fig. 10. The $\overline{K G}$ calculated as per Schneekluth's method [2] is given as input while computing $L C G_{\mathrm{LS}}$.

The damage stability calculation for general cargo ships will be described. The ships under this category are bulk carrier, container ship and pure car carrier. For general cargo ships, damage stability is checked as described in Table 8 . The probabilistic methodology is used for this purpose. The probability of damage is estimated with factors that affect the 
three-dimensional damage extent of the ship with the given watertight subdivision (transverse, horizontal and longitudinal). The damage parameters, such as longitudinal, vertical and transverse extent are determined based on the geometric layout of the subject ships. Single/ multiple compartment damage are considered as per the rule requirement. Unlike the deterministic damage stability computation which is primarily based on ship's length, there is no restriction on single, two compartment damage in probabilistic damage stability calculations. Similarly, there is no restriction on machinery compartment being part of one or two compartment damage. Also, permeability values of each compartment, tank and cargo space are explicitly given as input for the damage stability [3]. The key points or air vent for all the tanks are mentioned as per requirement, minimum $760 \mathrm{~mm}$ height from the main deck. This key point is taken as input to calculate the immersion angle [13]. The required subdivision index depends on ship's length as shown in Eq. 8 [3].

$$
\begin{array}{ll}
R=\left(0.002+0.0009 L_{\mathrm{S}}\right)^{1 / 3} & \text { For } L_{\mathrm{S}}>100.0 \mathrm{~m} \\
R=\left[\frac{1}{\left(1+\frac{L_{S}}{100} \times \frac{R_{O}}{\left(1-R_{O}\right)}\right)}\right] & \text { For } 80.0 \mathrm{~m} \leq L_{S} \leq 100.0 \mathrm{~m}
\end{array}
$$

$R_{O}$ in Eq. $8 \mathrm{~b}$ is calculated as shown in Eq. 8a. The method of calculating attained subdivision index for a ship is expressed as shown in Eq. 9.

$$
A=0.4 A_{S}+0.4 A_{P}+0.2 A_{L}
$$

Where the subscripts $S, P$ and $L$ represent the three loading conditions and ' 0.4 ' and ' 0.2 ' are the weighting factors. In our case ' $S$ ' corresponds to the deepest subdivision draft, ' $P$ ' corresponds to the ballast departure draft and ' $L$ ' corresponds to the ballast arrival draft. It is understood that light draft ' $L$ ' should correspond to sailing condition only. The general formula for computing the attained index is shown in Eq. 10.

$$
A_{C}=\sum_{i=1}^{i=t} p_{i}\left(v_{i} s_{i}\right)
$$

The subscript ' $C$ ' represents one of the three loading conditions shown in Eq. 9. The subscripts ' $i$ ' represent each investigated damage or group of damages and ' $t$ ' is the number of damages to be investigated to calculate $A_{C}$ for the particular loading condition. The probability factor ' $p_{i}$ ' is dependent on the geometry of the watertight arrangement of the ship. In case of double hull ships, a reduction factor ' $r$ ' is computed based on the double hull geometry. The probability that only double hull space is flooded is shown in Eq. 11a. The probability that both the double hull space and adjacent inboard compartment is flooded is shown in Eq. 11 b.

$$
\begin{aligned}
& p_{i}=p_{i} * r \\
& p_{i}=p_{i} *(1-r)
\end{aligned}
$$

The factor ' $v_{i}$ ' is dependent on the geometry of the watertight arrangement (decks) of the ship and the draught of the initial loading condition. It represents the probability that the spaces above the horizontal subdivision will not be flooded. The factor ' $s_{i}$ ' is the survivability of 
the ship after the considered damage for a specific initial condition. It is computed as shown in Eq. 12.

$$
s_{i}=C \sqrt{\left[0.5\left(G Z_{\text {Max }}\right) \phi_{R}\right]}
$$

$$
\text { Where } \left.C=0 \quad \begin{array}{ll}
1 & \text { if } \phi_{\mathrm{E}} \leq 25^{\circ} \\
& \text { if } \phi_{\mathrm{E}}>30^{\circ} \\
\sqrt{\left(\frac{30-\phi_{E}}{5}\right)} & \text { otherwise }
\end{array}\right\}
$$

$\overline{G Z}_{\text {Max }}=$ Maximum positive righting lever (meters) within the range as given below but less than $0.1 \mathrm{~m}$.

$\phi_{R}=$ Range of positive righting lever beyond the angle of equilibrium (degrees) but not more than $20^{\circ}$. The range shall be terminated at the downflooding angle.

$\phi_{E}=$ final equilibrium angle of heel (degrees).

$s_{i}=0$; if anyone of the downflooding points gets submerged in equilibrium condition after damage.

The attained subdivision index is determined by adding the results from the three different loading conditions after assigning weight to each one of them. The weighting accounts for the corresponding percentage (40\% of summer draft, $40 \%$ of partial loaded draft, and $20 \%$ of lightship draft) of different loading operation [5]. The loading conditions are defined by their mean draught and trim. The attained subdivision index shall be higher than the required subdivision index. It is difficult to get a mathematical expression for the limiting $\overline{K G}$ and $L_{\mathrm{CG}}$ value from Eqs. 6 and 7 directly. An iterative procedure is followed to get the limiting $K G_{\mathrm{LS}}$ and $L C G_{\mathrm{LS}}$ from Eqs. 6 and 7. The limiting $K G_{\mathrm{LS}}$ obtained from intact stability rules is taken as input. The probabilistic damage stability calculations are then carried out. If the attained index is higher than the required index, the limiting $K G_{\mathrm{LS}}$ is retained. Else the $K G_{\mathrm{LS}}$ is decremented by $0.1 \frac{K G_{\mathrm{LS}}}{D} \%$ in steps and the calculations are repeated. The $K G_{\mathrm{LS}}$ which will satisfy all the damage stability rule requirements will be taken as the new limit. The $L C G_{\mathrm{LS}}$ lower/ upper limit obtained from intact stability rules is taken as input. The probabilistic damage stability calculations are then carried out for the two values of the $L_{\mathrm{CG}}$. 
If the attained index is higher than the required index, the limiting $L C G_{\mathrm{LS}}$ values are retained. Else the $L C G_{\mathrm{LS}}$ is decremented by $0.1 \frac{L C G_{\mathrm{LS}}}{L} \%$ in steps and the calculations are repeated. The upper/ lower values of $L C G_{\mathrm{LS}}$ which will satisfy all the rule requirements will be taken as the new limit. Each ship design is checked for survivability in case of damage. After summarizing all possible damage cases from the three load cases, the survivability are estimated for single/ multiple compartment flooding. For all the methods, safety of ships against sinking/ capsizing in case of loss of their watertight integrity is the main concern of regulatory bodies. The analysis is concluded by computing limits of $L C G_{\mathrm{LS}}$ and $K G_{\mathrm{LS}}$ for different loading condition. Finally, to evaluate survivability criteria, the attained subdivision index must be more than the required subdivision index.

\section{Results and discussion}

The upper and lower limit of $L C G_{\mathrm{LS}}$ for different ship types determined from intact stability regulations is shown in Fig. 11. The $L C G_{\mathrm{LS}}$ position varies according to types of ships, hull shape $\left(\mathrm{C}_{\mathrm{B}}, \mathrm{C}_{\mathrm{P}}\right)$ and location of midship section. Also, $L C G_{\mathrm{LS}}$ limits (upper and lower limits) depend on the length of ship, type of cargo which the ship can carry and the loading plan. It is noticed from the results, that the limiting range of $L C G_{\mathrm{LS}}$ becomes higher when the ship's length increases. The length of tanker vessel varies between $120 \mathrm{~m}$ to $160 \mathrm{~m}$ and $180 \mathrm{~m}$ to $250 \mathrm{~m}$ respectively, and the $L C G_{\mathrm{LS}}$ limits varies between $-0.032 L_{\mathrm{bp}}$ to $0.037 L_{\mathrm{bp}}$ and $-0.045 L_{\mathrm{bp}}$ to $-0.049 L_{\mathrm{bp}}$. Oil tanker's $L C G_{\mathrm{LS}}$ is located aft of amidships. The trend of chemical tanker and bulk carrier is also same. Figure 11 shows that $L C G_{\mathrm{LS}}$ limits widen, when the ship's length increases. Similarly, VLCC tanker's have widest $L C G_{\mathrm{LS}}$ limits from $-0.065 L_{\mathrm{bp}}$ to $-0.078 L_{\mathrm{bp}}$ aft of midship. Also, PCC ships have smallest $L C G_{\mathrm{LS}}$ limits, when compared with other ship types. As we discussed early, $L C G_{\mathrm{LS}}$ position also varies depending on the vessel draft. In short, ship's draft is directly proportional to cargo density. When the VLCC tanker loaded to designed draft, the $L C G_{\mathrm{LS}} 0.023 L_{\mathrm{bp}}$ aft of midship. If the same ship is loaded with lighter cargo, the draft get reduces. So, the $L C G_{\mathrm{LS}}$ is shifted approximately $0.055 L_{\mathrm{bp}}$ forward. When ship's draft reduces under water section area also varies, it has an effect on the position of $L C G_{\mathrm{LS}}$. The detailed analysis results shown in Fig. 11, crude oil tanker (dense cargo) have wider $L C G_{\mathrm{LS}}$ limits compared with chemical tanker (lighter cargo). The container ship's $L C G_{\mathrm{LS}}$ lies between midship to forward of midship. The trend of PCC and LPG carrier is also similar. Container and PCC ships have significant quantity of cargo loaded above the main deck of the vessel. As a result, $L C G_{\mathrm{LS}}$ also move towards forward compared with other ship types. Also, it is evident from Fig. 11 that container ships have $L C G_{\mathrm{LS}}$ limits forward of midship as compared with PCC ship. In case of PCC, due to extra steel ramps and decks on the forward side, the $L C G_{\mathrm{LS}}$ shifts 
forward. Similarly for LNG/ LPG carriers due to independent cargo tanks and their insulations, membrane tanks and their insulations $L C G_{\mathrm{LS}}$ shifts forward. In brief, the $L C G_{\mathrm{LS}}$ of volumetric carriers are located forward of midship, and for dead weight carriers they are located aft of midship.

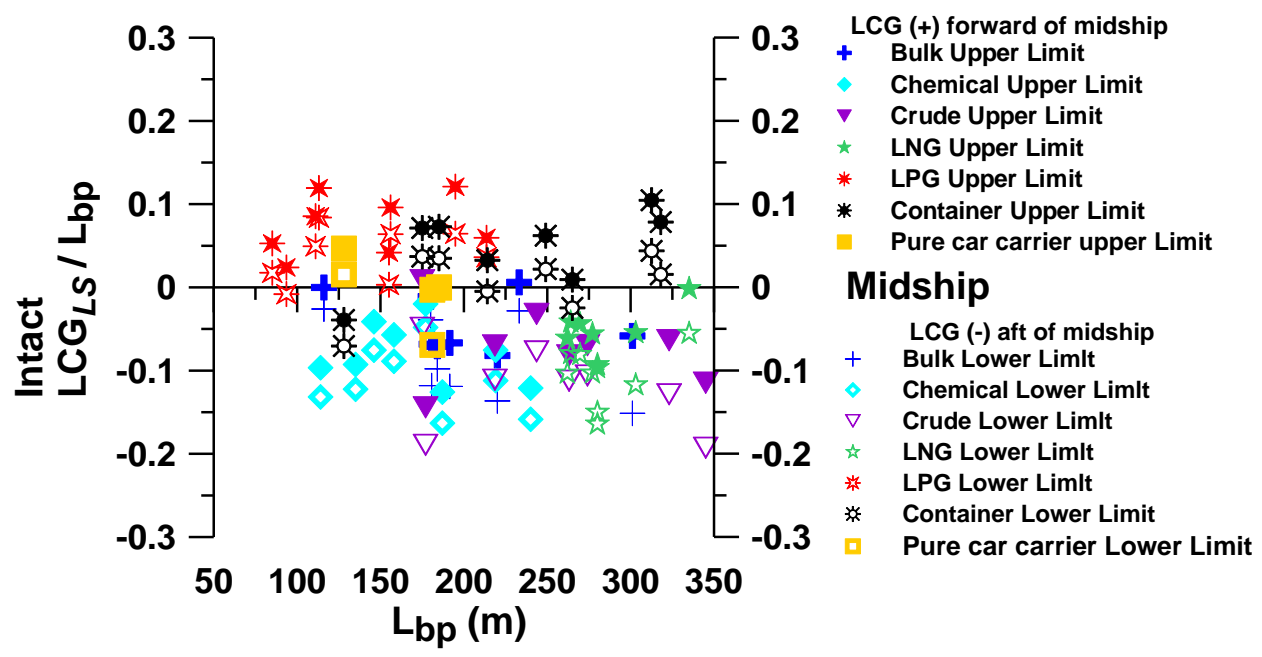

Fig. 11 Variation of intact $L C G_{\mathrm{LS}}$ with length for different ship types.

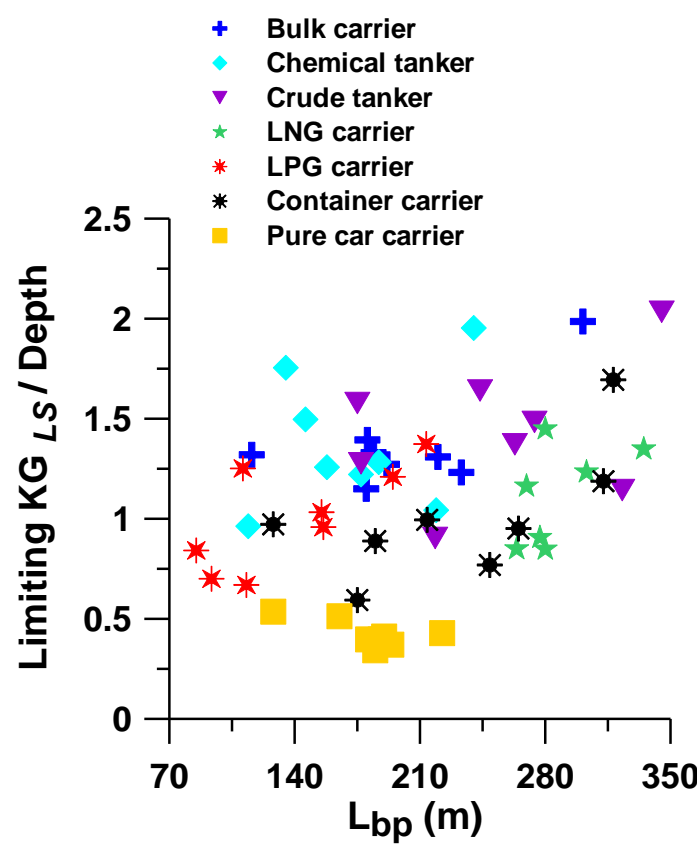

Fig. 12 Variation of limiting $K G_{\mathrm{LS}}$ (intact) with length for different ship types.

The limiting $K G_{\mathrm{LS}}$ for different ship types determined from intact stability regulations is shown in Fig. 12. The $K G_{\mathrm{LS}}$ non-dimensionalized by ship's depth is plotted in the graph. From the analysis, it is concluded that, the limiting $K G_{\mathrm{LS}}$ depends on cargo density and general arrangement. These two factors have significant contribution in limiting $K G_{\mathrm{LS}}$. Ships which are used to carry dense cargo have higher limiting $K G_{\mathrm{LS}}$. Dead weight carrier when loaded with high density cargo have low $\overline{K G}$. As a result, bulk carriers have high limiting $K G_{\mathrm{LS}}$ value followed by oil tanker. The next important factor, which will affect the 
limiting $K G_{\mathrm{LS}}$ value is general arrangement. As we discussed earlier, container, PCC ships have large quantity of cargo loaded above the main deck. As a result $\overline{K G}$ in loaded condition is high. Therefore, as shown in Fig. 12, these ships show lower limiting $K G_{\mathrm{LS}}$ value. It is observed that the ship's beam and depth also influence the limiting $K G_{\mathrm{LS}}$. As discussed before, a small increase in beam leads to a significant increase of $\overline{B M}$ and thereby the limiting $K G_{\mathrm{LS}}$ of the ship. Therefore, tankers and bulk carriers having lower $L / B$ ratio have high limiting $K G_{\mathrm{LS}}$ value. Alternately, container ships and car carriers having higher $L / B$ ratio have lower limiting $K G_{\mathrm{LS}}$ value. Ships having lower $L / B$ ratio will have higher $C_{B}$ and vice versa.

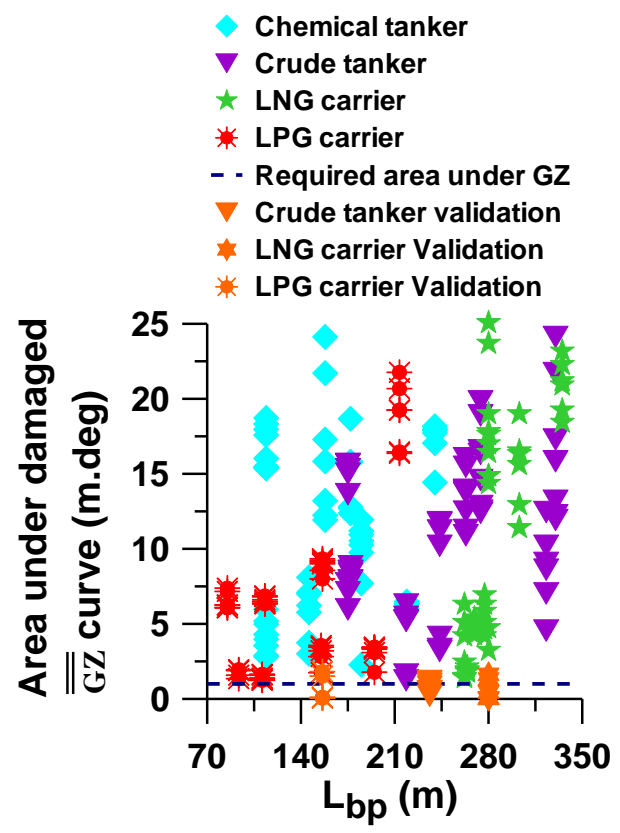

Fig. 13 Variation of area under $G Z_{\text {Damaged }}$ curve for different ship types.

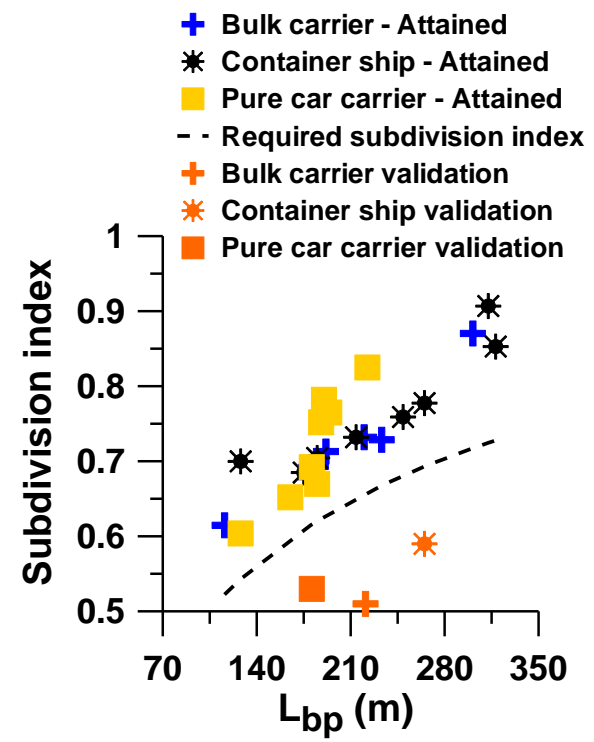

Fig. 14 Variation of subdivision index with length for different ship types. 
Now we will check the influence of damage stability criteria on the $K G_{\mathrm{LS}}$ and $L C G_{\mathrm{LS}}$. The deterministic damage stability criteria requirement applicable for different ship types are shown in Table 4 . The area under the $\overline{G Z}$ Damage curve for different damage cases is shown in Fig. 13. The results demonstrate the superior damage survivability characteristics of the vessel as compared to the minimum rule requirement. This shows that the internal subdivisions applied for the vessels are satisfactory. The probabilistic damage stability criteria requirement applicable for different ship types are shown in Table 4. The required subdivision index for each vessel was computed as per rule requirement. The attained subdivision index was computed for 3 different loading conditions for each ship type. These were then added after multiplying with the respective weighting factors as specified in the rules. The variation of subdivision index for different ship types is shown in Fig. 14. Figure 14 demonstrates that all the ship types have achieved probabilistic damage stability requirements. For the same length, the attained subdivision index for different ship types is different. There is contribution of geometric layout of the transverse and longitudinal subdivision bulkheads and the $\overline{G Z}_{\text {Damage curve. }}$

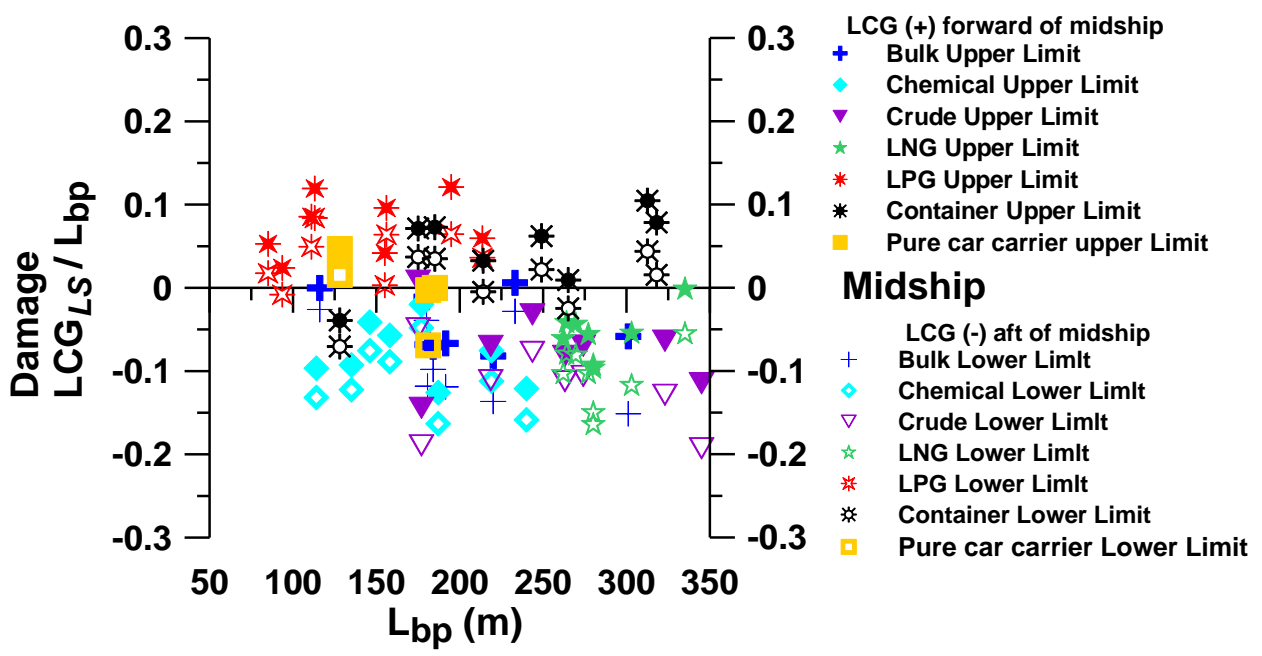

Fig. 15 Variation of $L C G_{\mathrm{LS}}$ with length for different ship types in damaged condition.

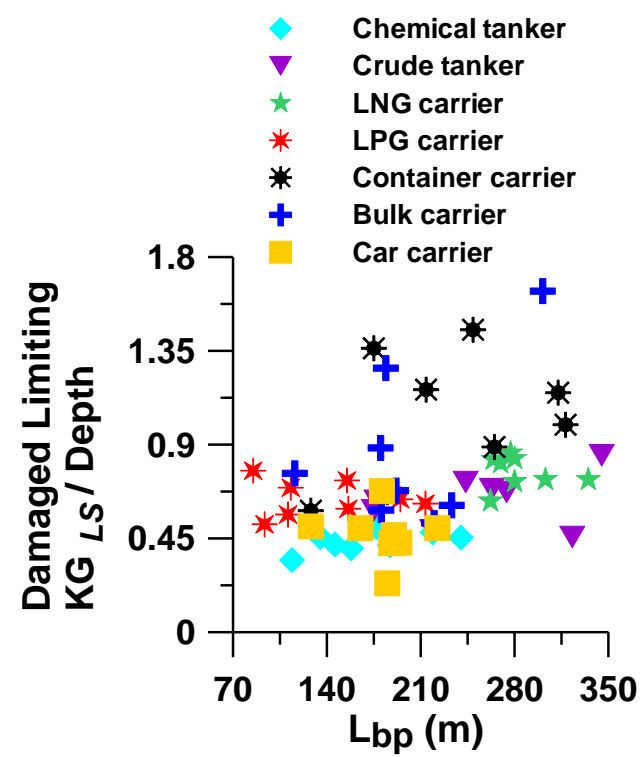

Fig. 16 Variation of limiting $K G_{\mathrm{LS}}$ with length for different ship types in damaged condition. 
The $L C G_{\mathrm{LS}}$ limits shown in Fig. 11, were checked for complying with damage stability requirements as described earlier. The new limits are shown in Fig. 15. It is observed that the $L C G_{\mathrm{LS}}$ limits determined from intact stability criteria also comply with the damage stability requirements. A definite trend for the limiting $L C G_{\mathrm{LS}}$ cannot be observed from this figure. However, it can be observed that $L C G_{\mathrm{LS}}$ shall be less than $0.1 L_{\mathrm{bp}}$ and greater than $0.2 L_{\mathrm{bp}}$. The $K G_{\mathrm{LS}}$ limits shown in Fig. 12 were checked for compliance with damaged stability requirements as described earlier. The trends of damaged limiting $K G_{\mathrm{LS}}$ is shown in Fig. 16. It is observed that the damaged limiting $K G_{\mathrm{LS}}$ values have decreased as compared to intact limiting $K G_{\mathrm{LS}}$ values. The damaged limiting $K G_{\mathrm{LS}}$ values have decreased up to $80 \%$ as compared with the intact limiting $K G_{\mathrm{LS}}$ values. After observing the trends of damaged limiting $K G_{\mathrm{LS}}$ in Fig. 16, it is seen that ships having higher freeboard have a higher damaged limiting $K G_{\mathrm{LS}}$. As the ship's size increases, the limiting $K G_{\mathrm{LS}}$ becomes higher. In case of damaged limiting $K G_{\mathrm{LS}}$, when holds are flooded with water, the cargo remains in ship increasing the displacement of container and bulk carrier vessels. The increased displacement leads to higher limiting $K G_{\mathrm{LS}}$ value as shown in Fig. 16. On the other hand, when damage occurs in crude oil tanker, LNG and LPG tanker, the cargo escapes into sea or atmosphere decreasing the displacement of vessels. The decrease of displacement reduces the limiting $K G_{\mathrm{LS}}$ value as shown in Fig. 16. From Fig. 16 it is observed that for some ship types limiting $K G_{\mathrm{LS}} / D$ is $>1.0$. For merchant ships this is an unlikely scenario. This is because most of the hull weight is located at a height less than $D$. Only the accommodation weight is located at a height above $D$. But accommodation weight is much less as compared to other lightship weight components. In merchant ships the lightship weight is usually much less than the deadweight component. Most of the deadweight components are located at height less than $D$ except in case of some volumetric carriers. Therefore, we have the benefit of keeping the $K G_{\mathrm{LS}}$ higher, although it will never be utilized during actual ship design.

The present work is validated for each one of the ship designs, namely tanker, bulk carrier LNG/ LPG carrier, container and car carrier. One unique vessel $\left(9^{\text {th }}\right.$ design $)$ is selected for validation for oil tanker and bulk carrier. While for the other ship types the validation vessel is chosen from the existing ship designs. The selected vessels are designed as per the general arrangement and criteria requirement as we discussed earlier. For validation, $L C G_{\mathrm{LS}}$ is assumed as $0.3 L_{\mathrm{bp}}$ (forward of midship) for all the investigated ship types. This $L C G_{\mathrm{LS}}$ is outside the limit shown in Fig. 15. With this value of $L C G_{L S}$ stability criteria requirements are checked. During this time the $\overline{K G}$ is kept as actual value. The results are presented in Fig. 13. Figure 13 shows that crude oil tanker, and LNG/ LPG carriers do not meet the stability requirements when $L C G_{\mathrm{LS}}=0.3 L_{\mathrm{bp}}$. Similarly, it can be noticed from Fig. 14 that bulk carrier, container and PCC ships also do not meet the stability requirements. When $L C G_{\mathrm{LS}}$ is kept outside the limit shown in Fig. 15, vessels experience unusual trim. The excessive trim causes the vessel to fail to meet the stability requirements shown in Fig. 13. Similarly, validation is carried out by assuming $K G_{\mathrm{LS}}$ above the limit shown in Fig. 16 ( $K G_{\mathrm{LS}}=0.3 D$ to $0.4 D$ ). During this time, the $L C G_{\mathrm{LS}}$ is kept as actual value. The higher $K G_{\mathrm{LS}}$ again causes the vessels to fail to meet the damage stability requirement as shown in the Fig. 13. The lightship weight is much less as compared to the deadweight for nearly all 
the merchant ships. However, it can be observed that if $L C G_{\mathrm{LS}}$ and $K G_{\mathrm{LS}}$ exceed beyond certain limits then the vessels will fail to meet the stability requirements. Therefore it is important to keep this in consideration when designing new ship type.

\section{Conclusions}

A systematic investigation of the lightship weight distribution, limiting $L C G_{\mathrm{LS}}$ and limiting $K G_{\mathrm{LS}}$ of different types of ships was carried out. Fifty eight ships of different types and capacity was used in the analysis. The vessels were evaluated by applicable intact and damage stability rules. On the basis of the analysis various ship designs are categorized in the form of limiting $L C G_{\mathrm{LS}}$ and $K G_{\mathrm{LS}}$.

Designers can identify the limits of design characteristics like hull, outfit, machinery weights, HFO, diesel, fresh water, ballast water capacities, main engine power and accidental oil outflow for a given vessel. Hence these results can be applied for the internal spaces arrangement and distribution of weight. The results of the analysis are presented in the number of graphs, which can give valuable guidance to the designer when verifying the $L C G_{\mathrm{LS}}$ and $K G_{\mathrm{LS}}$ limits of the vessel at the early stages of design.

In $L C G_{\mathrm{LS}}$ analysis, the intact and damage stability rules give the same range of limiting forward and aft limits of $L C G_{\mathrm{LS}}$. The $L C G_{\mathrm{LS}}$ for gas carriers, container ships and PCCs are relatively more towards the forward side as compared to bulk carriers and oil tankers. In $K G_{\mathrm{LS}}$ analysis, the damage stability rules give a lower limiting values of $K G_{\mathrm{LS}}$ as compared to intact stability rules.

For merchant ships, lightship weight is less than the deadweight. Amongst merchant ships, for deadweight carrier lightship weight is much less than the deadweight as compared to volumetric carriers. Therefore for deadweight carriers $K G_{\mathrm{LS}}$ limit may come higher than the ship's depth. This scenario is unlikely because $K G_{\mathrm{LS}}$ should be within ship's body dimensions. Besides the lightship weight, and limiting $K G_{\mathrm{LS}}$ and $L C G_{\mathrm{LS}}$, its distribution along the ship's length is also important. This will have a significant influence on the variation of shear force and bending moment in waves. This will be investigated in our future work. 


\section{Reference}

[1] Papanikolaou A. Ship Design Methodologies of Preliminary Design. Springer Publisher (2014). https://doi.org/10.1007/978-94-017-8751-2

[2] Schneekluth H. Ship design. Koehler, Herford (1985).

[3] SOLAS. Amendments to the International Convention for the Safety of Life at Sea, 1974, As Amended, Resolution MSC. 216 (82), (2006).

[4] Simopoulos G., Konovessis D., Vassalos D. Sensitivity analysis of the probabilistic damage stability regulations for RoPax vessels. Journal of Marine Science and Technology, Springer Japan, Vol. 13, pp. 164 - 177, (2008). https://doi.org/10.1007/s00773-007-0261-X

[5] Vassalos D. Damage stability and survivability - "nailing” passenger ship safety problems. Ships and Offshore Structures, Vol. 9, pp. 237 - 256, (2014). https://doi.org/10.1080/17445302.2013.780397

[6] Solem S., Fagerholt K., Erikstad S. O., Patricksson Ø. Optimization of diesel electric machinery system configuration in conceptual ship design. Journal of Marine Science and Technology, Springer Japan, Vol. 20, pp. 406 - 416, (2015). https://doi.org/10.1007/s00773-015-0307-4

[7] Lin C. K., Shaw H. J. Preliminary parametric estimation of steel weight for new ships. Journal of Marine Science and Technology, Springer Japan, Vol. 21, pp. 227 -239, (2016). https://doi.org/10.1007/s00773015-0345-y

[8] Čudina P., Bezić A. Reefer Vessel Versus Container Ship, Brodogradnja, Vol. 70, No. 1, pp. 129 - 141 , (2019). https://doi.org/10.21278/brod70109

[9] Kalajdžić M., Momčilović N. A Step Toward the Preliminary Design of Seagoing Multi-Purpose Cargo Vessels, Brodogradnja, Vol. 71, No. 2, pp. 75 - 89, (2020). https://doi.org/10.21278/brod71205

[10] Taylor D. W. Speed and power of ships. Wiley, New York (1943).

[11] Papanikolaou A. Anastassopoulos K. Ship design and outfitting I. National Technical University of Athens, Greece (2002).

[12] American Bureau of Shipping Rules for Building and Classing Steel Vessels, Part 3, Chapter 2, Section 1, pp. 24 - 27 (2002).

[13] ICLL, IMO Protocol relating to the International Convention on Load Lines (1966).

[14] MARPOL consolidated Edition (2006) International Convention for the Prevention of Pollution from Ships, 1973. MARPOL consolidated Edition 2006.

[15] Ventura M. Estimation Methods for Basic Ship Design. In: University Lecture Notes in Instituto Superior Técnico (2007).

[16] Völker H. Entwerfen von Schiffen Handbuch der Werften. In: vol XII. HANSA. Hamburg (1974).

[17] Molland A. F. The Maritime Engineering Reference Book: A Guide to Ship Design, Construction and Operation. Butterworth-Heinemann, Portugal (2008).

[18] Papanikolaou A. Ship design methodologies of preliminary ship design. Symeon Publisher, Athens, Greece (2009).

[19] MARPOL New Regulation 12 A - Oil fuel tank protection, (2006).

[20] Explanatory notes on matters related to the accidental oil outflow performance under regulation 23 of the revised MARPOL Annex I. Resolution MEPC. 122 (52), (2004).

[21] Amendments to the International Code for the Construction and Equipment of Ships Carrying Liquefied Gases in Bulk, Resolution MSC. 370 (93) (2014).

\section{Nomenclature}

$B$
Attained subdivision index

Breadth of ship

Distance between center of buoyancy to metacenter 


\begin{tabular}{|c|c|}
\hline$B / T$ & Ratio of breath to draft \\
\hline$C_{\mathrm{B}}$ & Block coefficient \\
\hline$C_{\mathrm{P}}$ & Prismatic coefficient \\
\hline$C_{\mathrm{M}}$ & Midship section coefficient \\
\hline$D$ & Depth of ship \\
\hline $\mathrm{d} D$ & Deepest subdivision draught \\
\hline $\mathrm{dP}$ & Partial subdivision draught \\
\hline $\mathrm{dL}_{\mathrm{L}}$ & Light service draught \\
\hline$F r$ & Froude number \\
\hline FEU & Forty equivalent units \\
\hline$\overline{G M}$ & Distance between center of gravity to metacenter \\
\hline$\overline{G Z}$ & Righting lever \\
\hline$\overline{G Z}_{\operatorname{Max}}$ & Maximum positive righting lever \\
\hline$\overline{\mathrm{GM}}_{\mathrm{T}}$ & Transverse metacentric height \\
\hline $\mathrm{HFO}$ & Heavy fuel oil \\
\hline IGC & International Gas Carrier Code \\
\hline IMO & International Maritime Organization \\
\hline$\overline{K G}$ & Distance between Keel to center of gravity \\
\hline$K G_{\mathrm{LS}}$ & Lightship Keel to center of gravity distance \\
\hline$L_{\mathrm{bp}}$ & Length between perpendiculars \\
\hline$L_{\mathrm{S}}$ & Length of ship \\
\hline LNG & Liquefied natural gas \\
\hline LPG & Liquefied petroleum gas \\
\hline$L / D$ & Ratio of length to depth \\
\hline$L / B$ & Ratio of length to breath \\
\hline$L_{\mathrm{CG}}$ & Longitudinal center of gravity \\
\hline$L C G_{\mathrm{LS}}$ & Lightship longitudinal center of gravity \\
\hline$L_{\mathrm{CB}}$ & Longitudinal center of buoyancy \\
\hline MARPOL & International Convention for the Prevention of Pollution from Ships \\
\hline$M_{\mathrm{TC}}$ & Moment to change trim by $1 \mathrm{~cm}$ \\
\hline OPA & Oil pollution act \\
\hline $\mathrm{O}_{\mathrm{B}}$ & Bottom oil outflow \\
\hline $\mathrm{O}_{\mathrm{M}}$ & Mean oil outflow \\
\hline $\mathrm{O}_{\mathrm{S}}$ & Side oil outflow \\
\hline$P$ & Propulsive power \\
\hline
\end{tabular}




$\begin{array}{ll}p_{i} & \text { Probability factor } \\ r & \text { Reduction factor } \\ R & \text { Required subdivision index } \\ s_{i} & \text { Survivability factor } \\ T & \text { Draft of ship } \\ \text { TEU } & \text { Twenty equivalent units } \\ V & \text { Speed of ship } \\ \mathrm{W}_{\mathrm{LS}} & \text { Weight of lightship } \\ \mathrm{W}_{\mathrm{ME}} & \text { Weight of all the machinery located in the engine room } \\ \mathrm{W}_{\mathrm{OT}} & \text { Weight of the equipment, outfit, deck machinery, etc. } \\ \mathrm{W}_{\mathrm{ST}} & \text { Weight of the hull structure, the superstructure and the outfit steel } \\ & \text { (machinery foundations, supports, masts, ladders, handrails, etc.). } \\ \phi_{R} & \text { Range of positive righting lever beyond the angle of equilibrium } \\ \phi_{E} & \text { Final equilibrium angle of heel } \\ \Delta & \text { Displacement of ship }\end{array}$

Submitted: $\quad$ 15.10.2019. Author 1, Sree Krishna Prabu Chelladurai

Accepted: $\quad 20.08 .2020$

Research scholar

Department of Ocean Engineering \& Naval Architecture Indian Institute of Technology Kharagpur

Kharagpur-721302, West Bengal, India

Author 2, Dr. Vishwanath Nagarajan,

Associate Professor,

Department of Ocean Engineering \& Naval Architecture Indian Institute of Technology Kharagpur

Kharagpur-721302, West Bengal, India

email: vishwanath_n@naval.iitkgp.ernet.in

Author 3, Om Prakash Sha

Professor,

Department of Ocean Engineering \& Naval Architecture Indian Institute of Technology Kharagpur

Kharagpur-721302, West Bengal, India 